\title{
Exploring the Effects of Microalgal Biomass on the Oil Behavior in A Sand-Water System
}

\author{
Azar Vahabisani
}

A Thesis

in

The Department of

Building, Civil and Environmental Engineering

Presented in Partial Fulfillment of the Requirements for the Degree of Master of Applied Science (Civil Engineering) at Concordia University

Montréal, Quebec, Canada

December 2020

(C) Azar Vahabisani, 2020 


\section{CONCORDIA UNIVERSITY}

School of Graduate Studies

This is to certify that the thesis prepared

By: $\quad$ Azar Vahabisani

Entitled: Exploring the Effects of Microalgal Biomass on the Oil Behavior in A Sand-Water System

and submitted in partial fulfillment of the requirements for the degree of

\section{Master of Applied Science (Civil Engineering)}

Complies with the regulations of the University and meets the accepted standards with respect to originality and quality.

Signed by the final examining committee:

Dr. Zhi Chen Chair

Chair's name

Dr. Fereshteh Mafakheri Examiner

Examiner's name

$\begin{array}{ll}\text { Dr. Zhi Chen_ } & \text { Examiner } \\ \text { Examiner's name } & \text { Supervisor } \\ \text { Dr. Chunjiang An_ } & \end{array}$

Approved by Dr. Michelle Nokken Chair of Department or Graduate Program Director 2020 Dr. Mourad Debbabi

Dean of Faculty 


\title{
ABSTRACT \\ Exploring the Effects of Microalgal Biomass on the Oil Behavior in A Sand-Water System
}

\begin{abstract}
Azar Vahabisani
This study focused on the impact of microalgal biomass on the oil behavior in a sand-water system. The microalgal biomass was characterized and the interaction between microalgal biomass and oil was analyzed through FTIR. The effects of different conditions including microalgal biomass dose, $\mathrm{pH}$, temperature and salinity on the oil behavior were investigated. A two-level factorial analysis was also used to further explore the interactions of these conditions. The microalgal biomass was found to be the most influential parameter for the residual crude oil on sand. Higher microalgal biomass dose resulted in less residual oil on sand. The remaining oil decreased with increasing solution $\mathrm{pH}$ from 4 to 7, and an increase of remaining oil was observed when the $\mathrm{pH}$ was further increased above 7. In addition, temperature and salinity could affect the removal of crude oil in the presence of microalgal biomass. Increasing the temperature up to $30^{\circ} \mathrm{C}$ could result in less residual oil on sand compared with that at $5{ }^{\circ} \mathrm{C}$. High salinity attributed to more oil removal from contaminated sand was more favorable than that at low salinity. Different mechanisms are related to oil removal and the behaviors of oil in this sand-water system could be influenced by the solution chemistry. The results of this study indicate that the presence of algae in the oiled shoreline can be considered in the comprehensive evaluation of spill risk and prediction of oil fate.
\end{abstract}




\section{TABLE OF CONTENTS}

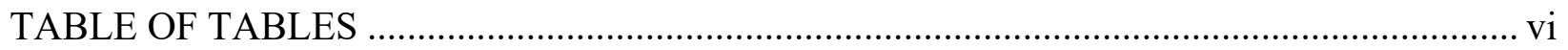

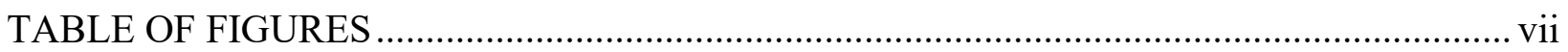

LIST OF ABBREVIATIONS ..............................................................................................

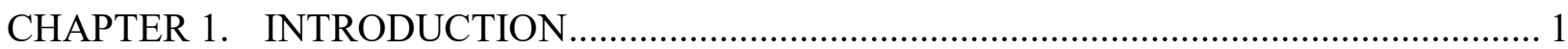

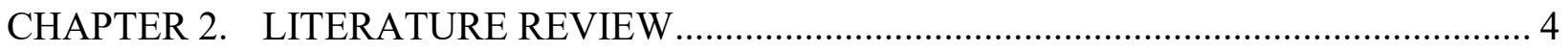

$2.1 \quad$ Oil spill and response …………........................................................................... 4

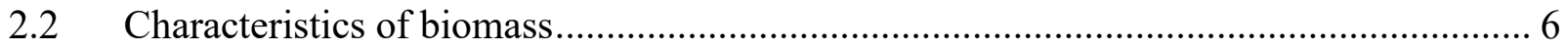

2.3 Removal of petroleum pollutants from water using algae-derived adsorbents .............. 11

2.3.1 Removal of crude oil using algae-derived adsorbents .............................................. 11

2.3.2 Removal of PAHs using algae-derived adsorbents ............................................... 13

2.4 Removal of petroleum pollutants from water using adsorbents derived from fungi, and shells 17

2.4.1 Removal of oil using adsorbents derived from fungus, bacteria and shells .............. 17

2.4.2 Removal of PAHs using adsorbents derived from fungus, bacteria and shells .......... 18

2.5 Major factors which can impact the process .............................................................. 20

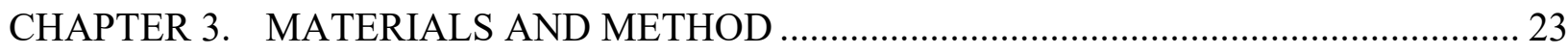

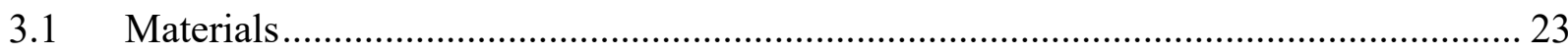

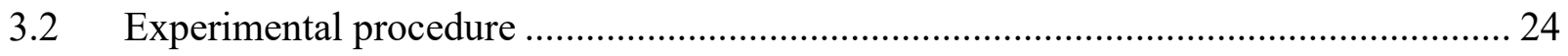

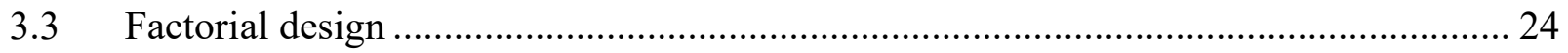

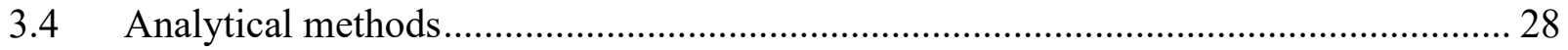

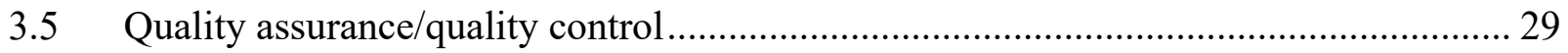

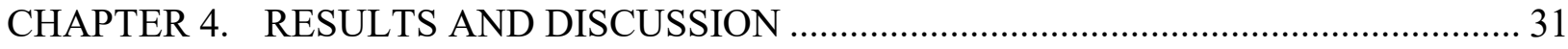

4.1 Characterization of microalgal biomass interacted with oil.......................................... 31

4.2 Effect of microalgal biomass dose on oil behavior ........................................................ 35 


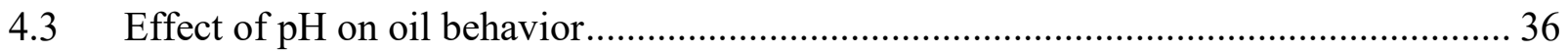

4.4 Effect of temperature on oil behavior ............................................................. 38

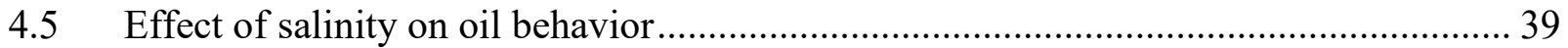

4.6 Factorial analysis of environmental conditions and its implications ......................... 40

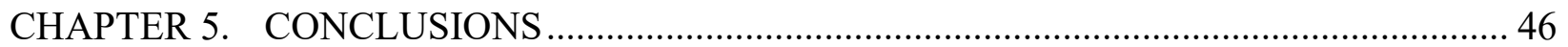

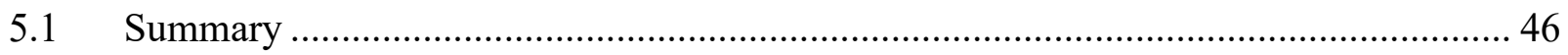

5.2 Recommendation for future study ................................................................... 46

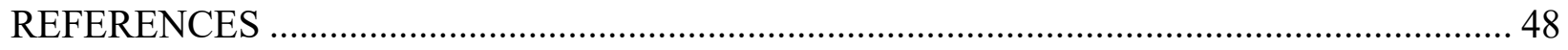




\section{TABLE OF TABLES}

Table 2-1 Use different types of algae-derived adsorbents in the removal of petroleum pollutants

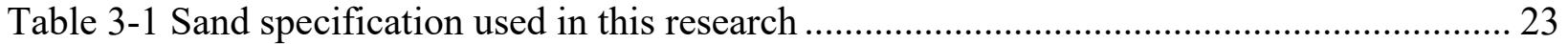

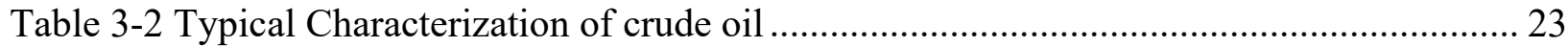

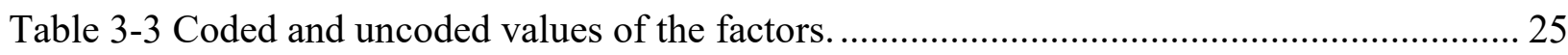

Table 3-4 Coded levels and corresponding values for factorial design matrix............................ 26

Table 4-1 Wavenumber $\left(\mathrm{cm}^{-1}\right)$ and assignment of the major bands of ATR-FTIR spectra of

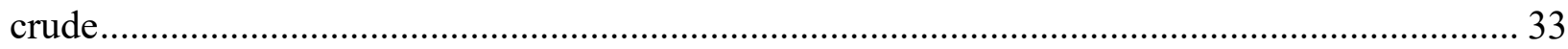

Table 4-2 Estimated effects and coefficients for residual oil remained on sand ......................... 42 


\section{TABLE OF FIGURES}

Figure 2-1 SEM images of (a) alga Ulva lactuca (Ibrahim et al., 2016), (b) dried Chlorella vulgaris (El-Sheekh et al., 2019), (c) E. intestinalis biomass (Boleydei et al., 2018) ................. 8 Figure 2-2 SEM images of (a) surface of heat dried fungus A. malaysianum biomass (Majumder et al., 2017), (b) dried flake of bacteri al cellulose (Gluconacetobacter sucrofermentans)

(Atykyan et al., 2020), (c) crab shell powder (Cai et al., 2019) 10

Figure 2-3 Adsorption, chelation/complexation and surface precipitation are different processes involved in biosorption 12

Figure 2-4 Sketch picture of bacterial chemotactic biosorption (Meng et al., 2019) 18

Figure 4-1 (A) SEM image of C. vulgaris cell, (B) Energy Dispersive X-Ray Spectroscopy (EDS) of C. vulgaris cell, (C) Particle size analysis of C. vulgaris biomass 32

Figure 4-2 ATR-FTIR spectra for crude oil, algae, and crude oil * algae (A). Microscopic imaging (B1, B2) and FTIR spectromicroscopic imaging for samples of algae, and crude oil * algae at 3001-2765 cm-1(C1, C2), 1490 - $1326 \mathrm{~cm}-1$ (D1, D2), $1721-1694 \mathrm{~cm}-1$ (E1, E2) ..... 34 Figure 4-3 The effect of biomass dose on the oil behavior in a sand-water system. Error!

\section{Bookmark not defined.}

Figure 4-4 The effect of $\mathrm{pH}$ on the oil behavior in a sand-water system.................................. 37

Figure 4-5 The effect of temperature on oil behavior in a sand-water system ........................ 39

Figure 4-6 The effect salinity on oil behavior in a sand-water system .................................. 40

Figure 4-7 Pareto chart for standardized effects for Residual oil remained on sand .................. 43

Figure 4-8 (A-D) Main plot for four factors, (E-J) interaction effect plot for each two factors... 45 


\section{LIST OF ABBREVIATIONS}

$\begin{array}{ll}\text { ANOVA } & \text { One-way analysis of variance } \\ \text { BaP } & \text { Benzopyrene } \\ \text { DI } & \text { Deionized } \\ \text { EDX } & \text { Energy Dispersive X-ray } \\ \text { FTIR } & \text { Fourier Transform Infra-Red } \\ \text { HOC } & \text { Hydrophobic organic compound } \\ \text { NAP } & \text { Naphthalene } \\ \text { OPA } & \text { Oil particle aggregate } \\ \text { PAH } & \text { Polyaromatic hydrocarbon } \\ \text { PHE } & \text { Phenanthrene } \\ \text { PYR } & \text { Pyrene } \\ \text { SEM } & \text { Scanning Electron Microscopy } \\ \text { XPS } & \text { X-ray Photo Electron Spectroscopy } \\ \text { UV-Vis } & \text { Ultraviolet-visible } \\ \text { XPS } & \text { Energy Dispersive X-ray } \\ \text { XRD } & \text { X-ray Diffraction }\end{array}$




\section{CHAPTER 1. INTRODUCTION}

One of the most important threats to the ocean ecosystem is oil spills. Most marine oil spills can be resulted from accidental leakage from supertankers and pipelines, oil drilling and some natural events (An et al. 2017). Pushed by winds and currents, the spilled oil can often reach the shoreline, resulting in environmental and economic damage eventually (Chen et al. 2019). Such oil may strand at the high tide line, leaving black lines or globs of oil on the beach as the tide recedes. Rocks, beaches, or plants can coated by thick layer of oil, while small amount of oil can even remain in some shorelines for decades. For most spills on shoreline, natural removal and weathering processes could remove the majority of stranded oil within months or a few years. There are specific conditions which may delay normal physical removal or weathering processes (Owens et al. 2008). In recent years, some studies have been conducted to investigate the oil fate and behaviors in the shoreline contaminated by oil spill (Khan et al. 2004).

The complex patterns of water movement close to coasts tend to concentrate oil in certain areas. The fate of oil is dependent on various factors such as shoreline topography and composition, the exposure of oil to wave and tidal energy, and the characteristics of oil when it arrives (Sharma et al. 2020). The physical transport of spilled oil from the sea surface to the ocean bottom can be mediated by oil particle interaction (Muschenheim and Lee 2002). Suspended particulate matter and aggregates of detritus, living organisms and inorganic matter known as marine snow, play an important role through the adsorption of hydrocarbons and the association of dispersed oil droplets (Lee 2002; Passow and Ziervogel 2016). The particles less than $2 \mu \mathrm{m}$ with the capacity to bind hydrophobic compounds dominate free surface of natural waters, leading to a significant amount of oil sedimentation via agglomeration (Johnson et al. 2018). 87-98\% of spilled oil may change to "particulate" form, either incorporated into suspended particulate matter aggregates or as particulate free oil globules (Johnson et al. 2018).

As a special type of particulates, small organisms are widespread in the marine environment. The transport of oil can also be impacted by the existence of such small organisms. For example, oil can be translocated to benthic habitats through the active feeding of zooplankton (Tao et al. 2019). 
Algae are widely distributed in marine and shorelines ecosystems (Xin et al. 2020). Previous studies reported the sorption of contaminants on biomass derived from algae. The biomass obtained from saline or freshwater micro and/or macroalgae has been used as biosorbents for removing heavy metals, phenolic compounds, dyes, and aromatic hydrocarbons from water (Beolchini et al. 2006). The algal biomass contains various active sites with hydroxyl, carboxyl, and amine in their cell wall structure, making algae accessible for biosorption (Mishra and Mukherji 2012). Such structure can also result in the bonding of oil and algae (Gupta and Rastogi 2009). In the shoreline environment, algal biomass exists in both sea water and beach sediments. The presence of algae may impact the translocation of stranded oil on shoreline. Although many studies have been conducted to investigate the oil transport and fate in the marine environment, the impact of algae on the oil behaviors in contaminated shoreline has not been reported. The knowledge regarding the physiochemical nature of this impact at water-solid interface is still not available.

The passive uptake of pollutants from aqueous solutions by non-growing or non-living microbial mass can be used for the recovery and/or disposal of pollutants. The special surface properties of algae enable them to adsorb different kinds of organic pollutants from solutions. Biosorption (physical and chemical adsorption) takes place essentially in the cell wall. The main attractions of biosorption are high selectivity and efficiency, cost effectiveness and good removal performance. The raw materials which are either abundant (microalgae and sea weeds) or wastes from other industrial operations (fermentation wastes, activated sludge process wastes) can be used as biosorbents. Dead biomass cells may be stored or used for extended periods at room temperature without putrefaction. It is easy for operation and further treatment. The dead cells can show to pollutant accumulation to the same or greater extent than growing or resting cells (Aksu and Tezer 2005). Therefore, the Chlorella powder was used as a model in this study.

The present study aims to explore the impact of microalgal biomass on the oil behavior in a sandwater system. The microalgal biomass will be comprehensively characterized at first. The effects of shoreline environmental conditions including temperature, $\mathrm{pH}$, biomass dose and salinity will be investigated. The significant factors and their interactions will be explored based on factorial analysis. These results can be used to support the risk assessment for shoreline contaminated by 
oil spills. The thesis includes the comprehensive literature review on the biomass and pollutant behavior (Error! Reference source not found.); materials and methods for the experiments ( Error! Reference source not found.); results and discussion (Error! Reference source not found.), and Conclusions (CHAPTER 5). 


\section{CHAPTER 2. LITERATURE REVIEW}

\subsection{Oil spill and response}

Oil is one of the most important energy and raw material source for synthetic polymers and chemicals world-wide. There is risk of spillage with the potential to cause significant environmental impact whenever oil is explored, transported and stored and its derivatives are used. Pollution by petroleum oils affects many aspects such as sea life, economy, tourism and leisure activities because of the coating properties of these materials (Mokhtarian et al. 2010). When oil is spilled into a marine environment, it is subject to several processes including spreading, drifting, evaporation, dissolution, photolysis and formation of water-oil emulsions. Oil spreading is likely to occur, especially if the sea surface is still in the peculiar environment of rivers, pollutants are driven along the stream (Anderson 1997).

The majority of the stranded oil is removed for most spills within months or a few years due to natural removal and weathering processes (Tian et al. 2020). Small amounts of oil can persist for decades on some shorelines; 10-, 20-, and even 30-year old oil residues on coarse-sediment beaches have been documented for some spills. Oil spilled at sea initially spreads over the water surface as a slick a few millimeters thick. The volatile components in crude oil rapidly evaporate after spillage. This includes most of the toxic components. For example, it is estimated that at least $30 \%$ of the oil spilled by the Exxon Valdez (35,000 tonnes) evaporated into the atmosphere. As much as $40 \%$ of the Amoco Cadizoil (240,000 tonnes) disappeared in this way. The nature of the oil is an important factor in this respect. The lighter the oil the greater the power of evaporation to remove it from the sea surface. Over half the cargo of oil spilled by the Jessica in the Galapagos in 2001 was a light oil (diesel) (Gordon Jr et al. 1973). Oil spills also harm the beauty of polluted sites and the strong odor can be felt miles away it can affect the sea color and the landscape.

Because of the action of local or tidal currents in open seas or in harbors, the consequences of pollutants are often severe. Specific conditions or circumstances may delay or prolong normal physical removal or weathering processes but the amounts of oil that persist beyond a few years represent a very small fraction of the volume that was originally stranded (Pi et al., 2019; Liu et 
al., 2020a). Wind and current conspired to drive the oil slick away from the coast and the hot tropical sun caused almost all of the diesel to evaporate leaving just patches of the remaining cargo of fuel oil. It was partly for this reason that the spill was less of a disaster than originally feared. UV radiation in sunlight will oxidize some of the components present in oil, a process known as photolysis. The oxidation products include acidic and phenolic compounds, some of which may be more toxic than the original hydrocarbons (Lei et al. 2007).

Viscous oils spread more slowly than less viscous ones and therefore, water temperature, along with windspeed and sea conditions have an intense effect on the extent of oil spreading. The identification of those specific conditions or circumstances is an important component of the cleanup or treatment decision process to identify locations where it might be appropriate to remove or reduce the amount of residual oil if this is considered to be of concern for environmental or aesthetic reasons (Owens et al. 2008). As such, spreading is important in determining the fate of spilled oil through evaporation, emulsification and natural dispersion (Annunciado et al. 2005).

With the growing interest in environmental remediation, various approaches have been proposed for treating petroleum hydrocarbon contaminated sites. Among these treatment methods, soil washing has been proposed as a promising innovative remediation technology due to its potential for treating not only oil contaminated soils but also those contaminated by heavy metals (Wasko and Bratt 1991). Soil washing is less time consuming compared with bioremediation and phytoremediation, which are largely affected by climatic factors. The traditional soil washing process has been studied extensively in recent years, showing that it can be applied as an ex situ or in situ process, involving water or aqueous surfactant solutions to desorb and concentrate the contaminants into bulk liquid phase without chemically modifying them (Urum et al. 2004).

The toxicity of oil spills on contaminated soil is of a great concern especially on the environment, and this issue had been highlighted by several groups of researchers. Clearly, it could be seen that the oil spillage on soil greatly impacts the surrounding environments, which highlights the urgent need for effective removal of oil contaminant from soil. At present, most clean-up efforts for oil spill on soil and shoreline require mechanical and labor intensive methods as they may be a quick and simple solution to remove oil contaminants (Broman et al. 1983). However, there are many disadvantages associated to these methods such as the usage of high pressure washing to displace 
oil which may destroy the microbial populations, while the chemical sorbents and dispersants may be harsh to the environment. In addition, these mechanical methods are tedious, time consuming and are only capable of removing the oil contaminants up to a certain extent, leaving behind a large amount of oil adsorbed in the soil. These conventional first response actions are therefore not able to achieve efficient clean-up of oil spills under a short period of time (Lim et al. 2016). Therefore, there is an urgent need to investigate on other environmental-friendly remediation methods to remove oil contaminants in soil.

To date, there is a variety of technologies available for the remediation of oil contaminated soil, ranging from widely applied technologies such as solvent extraction, bioremediation and biosorption to the emerging technologies such as electro-kinetic remediation and sonication. The sorption technologies for oil contaminated soil can be classified into chemical and physicochemical methods. The following sections will discuss about the sorption technology with biomass in detail.

Various biosorbents including cattail fibers, rice husk, cotton fibers, Azolla filiculoides biomass, pomelo peel, straw biomass waste, and lignocellulosic biomass of pineapple leaves were used for the oil removal from aqueous solutions. The biomasses of micro- and macroalgae obtained from saline or freshwater have been reported as a suitable and available biosorbent for water decontamination polluted by different micropollutants (Boleydei et al. 2018).

Algae from marine and freshwater environment may have a special relevance for development of low cost sorbents for removal of oil. Interaction of algae with oil is also likely to affect the fate and transport of spilled oil in the environment and the fate of oil in oily wastewater treatment studies involving algae where significant accumulation of oil may occur on biomass.

\subsection{Characteristics of biomass}

Marine life is defined by its biodiversity, including many species about which relatively little is known. Indeed, there are many exceptional sources of microorganisms, including plants and animals, that exhibit unique features. With respect to biosorption, various living and non-living 
biomasses have been reported, such as algal biomass, fungi, and bacteria (Carolin et al. 2017). An ideal biosorbent will possess features such as availability, non-toxicity, high metal-binding capacity, large-scale usability, and regeneration/re-usability (Wang and Chen 2009). The adsorption properties of biosorbents, it should be noted, are dependent on their structural characteristics, e.g., pore distribution, specific surface area, and functional groups (Ramrakhiani et al. 2011). The chemical composition of the biomaterials, meanwhile, is affected by seasonal, temporal, and spatial variations of environmental factors such as water temperature, salinity, light, and nutrient availability (Peña-Rodríguez et al. 2011). The physical and chemical characteristics of biosorbents are important for understanding the metal-binding mechanism on the biomass surface. The characterization of the structure and surface chemistry of the biosorbent is of considerable interest for the development of adsorption and separation processes. Depending on the nature of the biosorbent, a variety of techniques are useful for this purpose, e.g., Fourier Transform Infra-Red (FTIR) spectroscopy, X-ray Photo Electron Spectroscopy (XPS), Scanning Electron Microscopy (SEM), X-ray Diffraction (XRD), Energy Dispersive X-ray (EDX) fluorescence spectrophotometry, and nitrogen sorption. To obtain the structure and complete description of the composition and morphology of the various biosorbents, these methods are commonly used in together (Arief et al. 2008).

\section{(i) Algae}

Algae refers to a large and diverse group of unicellular and multicellular organisms distributed in water bodies and terrestrial environments. Algae contain chlorophyll and carry out oxygenic photosynthesis. The colonial forms of algae occur as aggregates of cells in which each cell shares common functions and properties, including the storage products they utilize as well as the structural properties of the cell walls, where the characteristics of a given algal functional group may affect the adsorption process (Pathak et al. 2018; Rangabhashiyam et al. 2014).

Algal biomass is the most widely employed of any biosorbent material. Figure 2-1 shows the SEM images of alga Ulva lactuca (Ibrahim et al. 2016), dried Chlorella vulgaris (El-Sheekh et al. 2019), E. intestinalis biomass (Boleydei et al. 2018). As no treatment is required for algae, it is considered a low-cost biosorbent, and its cell wall characteristics give it a high metal ion-binding capacity (Anastopoulos and Kyzas 2015). Non-living algal biomass has been reported to be more 
promising as compared to living algae because of its higher metal ion sorption capacity and rate, and given that it does not require nutrients grown in a medium (Zeraatkar et al. 2016). Different types of algae, such as marine algae, marine red macroalgae, marine brown macroalgae, and freshwater green macroalgae, have been reported as effective biosorbents. Brown algae in particular have been reported to have good biosorption capacity due to the presence of alginates in their cell walls (Bilal et al. 2018).
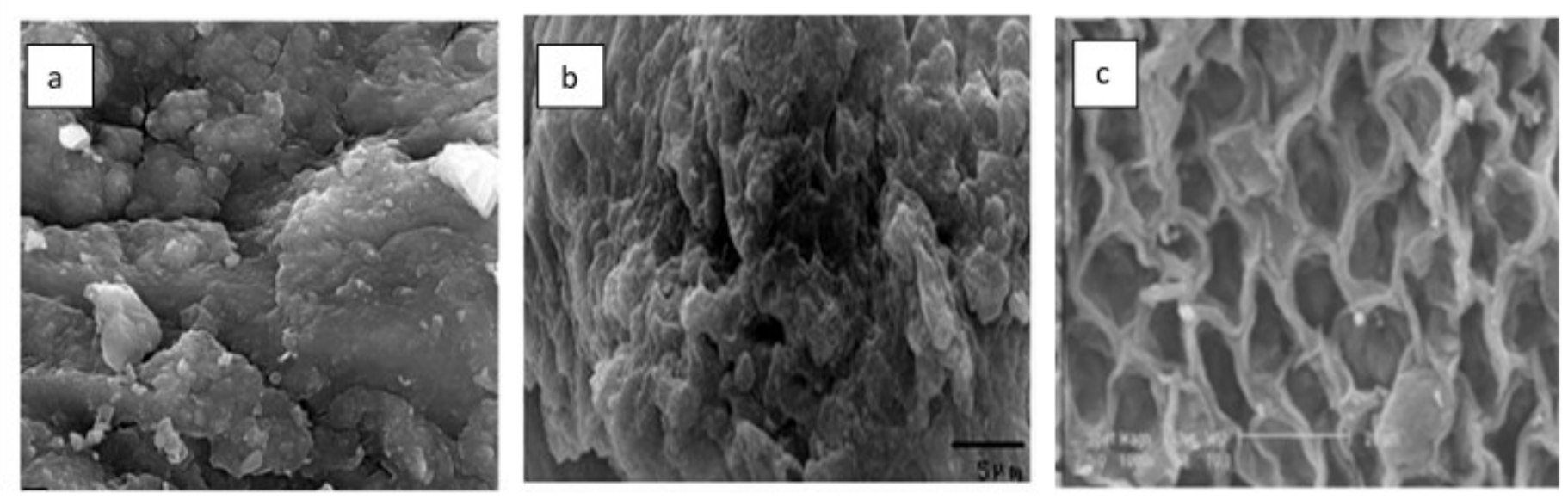

Figure 2-1 SEM images of (a) alga Ulva lactuca (Ibrahim et al., 2016), (b) dried Chlorella vulgaris (El-Sheekh et al., 2019), (c) E. intestinalis biomass (Boleydei et al., 2018)

Algal has many functional groups, such as carboxyl, hydroxyl, and sulphate groups, that are categorized by their complex polysaccharides, protein and, lipid components (Ghadiryanfar et al. 2016; Sarı and Tuzen 2008), which in turn are likely to have some bearing on nature of the adsorption process for the various functional groups (Henriques et al. 2017). Since algae do not require nutrients and can be exposed to environments with high toxicity, they have been used widely in various industrial applications in order to reduce hazardous organic and inorganic pollutants and biosorption often makes use of dead biomasses of algae (Crist et al. 1981).

A number of studies have shown that carbohydrates are the main structural component of macroalgae biomasses. The total carbohydrate sources differ according to the species (HernándezGarcía et al. 2019; Ho et al. 2013; Mata et al. 2010; Nigam and Singh 2011). In a study which was conducted by Flores-Chaparro et al. (2017) they have been reported as accounting for $15.9 \%$, $16.02 \%$, and $11.8 \%$ of brown, green, and red macroalgae biomasses, respectively, followed by 
hemicellulose in the case of green (13.57\%) and red (9.30\%) macroalgae samples. For brown macroalgae, meanwhile, protein content has been reported as the second highest component at $13.4 \%$, whereas a lower protein content has been observed in green and red seaweeds $(2.8 \mathrm{e} 7.1 \%$ dry weight).

The cell walls of algae are complex networks of biopolymers consisting of a skeleton of crystalline and fibrous parts (cellulose, hemicellulose, etc.) and an embedding matrix of specific polysaccharides, proteoglycans, and other molecular components depending on the type of species. Because of the complexity of most macroalgae biopolymers, it is probable that several interactions between pollutants and active sites will passively occur in the system simultaneously (FloresChaparro et al. 2017).

(ii) Fungi and crab shells

Fungal cell walls are rigid and contain complex polysaccharides-namely, chitin (which adds structural strength) and glucans - that serve many functions, including providing cell rigidity and shape, metabolism, and ion exchange. Polysaccharides account for $80 \%$ to $90 \%$ of the fungal cell wall, with proteins, lipids, polyphosphates, and inorganic ions making up the wall-cementing matrix. Two layers have been observed in ultrastructural studies of the fungal cell walls (Arief et al. 2008). Bacteria are a major group of unicellular living organisms belonging to the prokaryotes, which are ubiquitous in soil and water and exist in symbiosis with other organisms. Bacteria have a relatively simple cell structure, lacking nuclei, but possessing cell walls (Seltmann and Holst 2013). The bacterial cell wall provides structural integrity to the cell, but differs from that of all other organisms due to the presence of peptidoglycan (poly- $N$-acetylglucosamine and $N$ acetylmuramic acid). The cell shape and rigidity of each bacterial cell wall are due to the peptidoglycan substance in their structure (Kolenbrander and Ensign 1968). Since the peptidoglycan is porous, it is also has been considered as an barrier to small substrates (Vijayaraghavan and Yun 2008).

Rae et al.(2009) investigated the adsorption performance of adsorbents derived from crab shells for the removal of $\mathrm{Hg}$ from acidic solutions and found them to be effective, rapid, and easily 
processed. Cai et al. (2019), meanwhile, found the microstructure of crab shell powder to be characterized by a fibrous structure and a loose, unevenly arranged surface. Chitin can be obtained from fungi, insects, lobsters, shrimps and krill, but the most abundant commercial source is the exoskeletons of crabs (No et al. 1989). Chitin is a strong but flexible nitrogen-containing polysaccharide. Chitin and chitosan have been recognized as effective biosorbents for concentrating radionuclides and heavy metals, because their amine and acetamido groups function as nonspecific binding sites (Tsezos 1983). Moreover, they are inexpensive and abundantly available. Chitin, it should be noted, is a natural polysaccharide consisting of (1-4)-2-acetamido2-deoxy-D-glucose units, while chitosan is its deacetylated derivative. The shell of the crab, Portunus trituberculatus, comprises (weight \%): calcium carbonate (58), chitin (17), protein (10), moisture (13), and other substances (2). With regard crab shell composition, Lee et al. (2004) showed the calcium carbonate and chitin in crab shell to be effective in the treatment of leadbearing wastewater, as calcium carbonate forms strong lead-carbonate precipitate while chitin acts as an adsorbent for the precipitate. Figure 2-2 shows surface of heat dried fungus $A$. malaysianum biomass (Majumder et al. 2017), dried flake of bacterial cellulose (Gluconacetobacter sucrofermentans) (Atykyan et al. 2020) and crab shell powder (Cai et al. 2019).
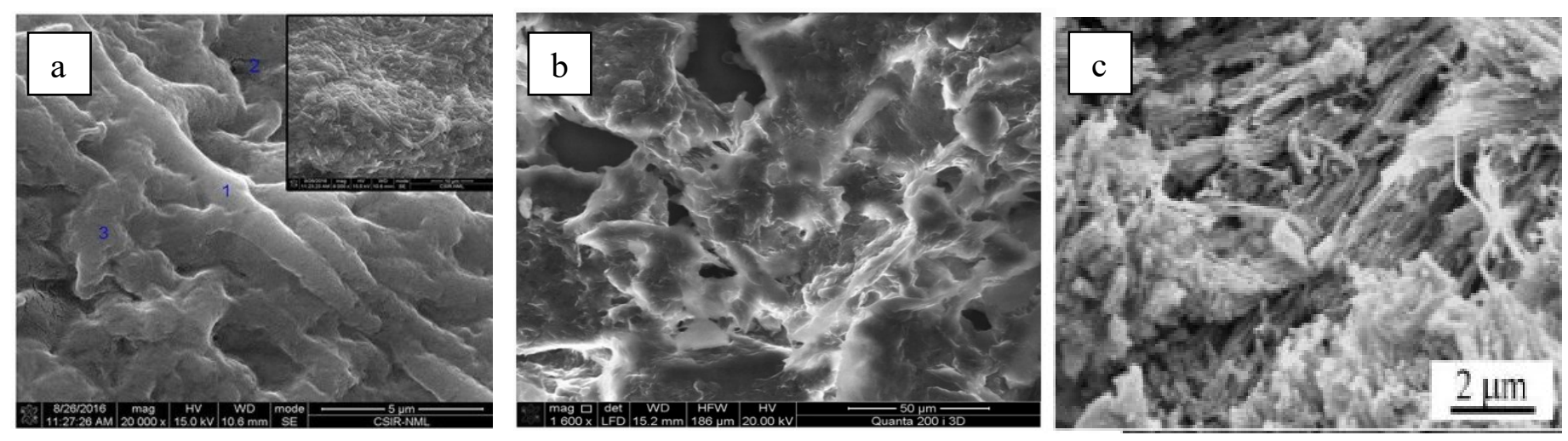

Figure 2-2 SEM images of (a) surface of heat dried fungus A. malaysianum biomass (Majumder et al., 2017), (b) dried flake of bacteri al cellulose (Gluconacetobacter sucrofermentans) (Atykyan et al., 2020), (c) crab shell powder (Cai et al., 2019) 


\subsection{Removal of petroleum pollutants from water using algae-derived adsorbents}

\subsubsection{Removal of crude oil using algae-derived adsorbents}

Mishra and Mukherji (2012) studied biosorption of diesel and lubricating oil using dead biomass of Spirulina sp. and Scenedesmus abundans. They observed the rate and extent of sorption in wellmixed batch systems containing oil $(0.1 \%$ to $2 \%, \mathrm{v} / \mathrm{v})$ and biomass $(0.1 \%)$ suspended in water. The sorption of diesel on Spirulina sp. was observed to be instantaneous. The Freundlich and Langmuir models, it should be noted, were found to be suitable for diesel sorption on algae but not for lubricating oil. A three-parameter model, meanwhile, was found to be suitable for all experimentally-generated isotherms, yielding maximum biosorption capacities for both diesel and lubricating oil in the range of $12 \mathrm{~g} / \mathrm{g}$ to $14 \mathrm{~g} / \mathrm{g}$ for a 12-day period of study. In another study, Boleydei et al. (2018) used an algal biomass of green macroalgae E. intestinalis as a biosorbent for decontamination of freshwater and seawater polluted by crude oil and spent oil. They reported that the maximum sorption capacity of both compounds by the biosorbent was higher in seawater than in freshwater. The spent engine oil, with a higher viscosity, showed better sorption efficiency compared to the less viscous crude oil under the given experimental conditions. Moreover, the adsorption data were found to be well fitted to both the pseudo-second-order kinetic model and the Langmuir isotherm model.

Different mechanisms have been reported for the removal of potentially toxic elements through biosorption (Bilal et al. 2018; Chojnacka 2010). Biosorption, as mentioned above, is a passive process that occurs at a faster rate than bioaccumulation. Adsorption, chelation/complexation, and surface precipitation have all been identified as sub-processes of biosorption (Figure 2-3), with the particular mechanism of biosorption being dependent upon the biomass being used for the removal (Flouty and Estephane 2012). 


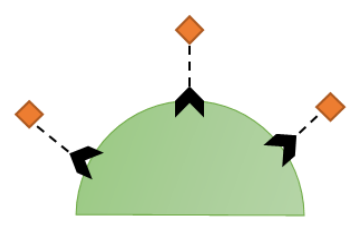

Electrostatic attraction

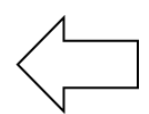

\section{Biosorption}
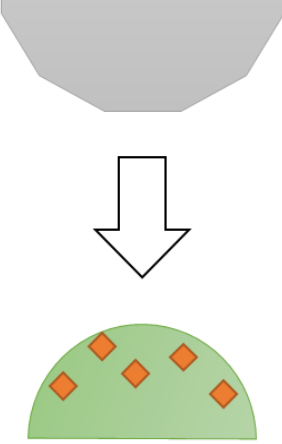

Physical adsorption
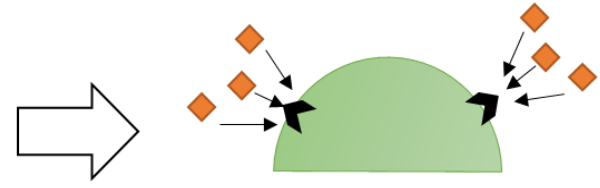

Chelation

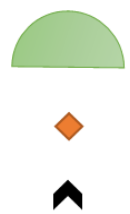

Biomass

Pollutants

Functional group

Figure 2-3 Adsorption, chelation/complexation and surface precipitation are different processes involved in biosorption

The principal mechanism involved in biosorption appears be physico-chemical binding of organic pollutants to the cell surfaces (cell adsorption), and this process does not require any metabolic energy (Avery et al. 1998). The initial contact is characterized by the ion-binding properties of the algal cell walls (Chu et al. 1997; McDonald and Trevors 1988). Algal cell walls offer a host of functional groups, including amino, carboxyl, sulphates, phosphates, and imidazoles associated with polysaccharides alginic acid and proteins for binding various pollutants (Ahmad et al. 2005a; Crist et al. 1981). Algal cell walls, it should be noted, possess an overall negative charge and have receptors capable of binding and attracting cations (Chu et al. 1997; Marbelia et al. 2016). Vandevivere and Kirchman (1993) have noted that the presence of extracellular polymeric substances and the fluidity of the membrane may also be key factors in adsorption. Moreover, Sijm et al. (1998) suggest that algae may also produce and excrete exudates consisting of a significant amount of organic materials, with these exudates binding to heavy metals and organic contaminants on the surface. 


\subsubsection{Removal of PAHs using algae-derived adsorbents}

Polycyclic aromatic hydrocarbons (PAHs) are ubiquitous pollutants in aquatic ecosystems. PAHs naturally occur in fossil fuels such as coal and petroleum, but they are also formed during the incomplete combustion of organic materials such as coal, diesel, wood, and vegetation (Chekroun et al. 2014). Researchers have reported biosorption of organic micropollutants, such as biosorption of low concentrations of fluoranthene and pyrene on various microalgae (Koelmans et al. 1995; Pathak et al. 2018). Lei et al. (2002) evaluated the efficiency of four microalgal species-Chlorella vulgaris, Scenedesmus platydiscus, Scenedesmus quadricauda, and Selenastrum capricornutumto remove fluoranthene $(1.0 \mathrm{mg} / \mathrm{L})$, pyrene $(1.0 \mathrm{mg} / \mathrm{L})$, and a mixture of fluoranthene and pyrene (each at a concentration of $0.5 \mathrm{mg} / \mathrm{L}$ ). Their study found the removal to be algal species-specific and toxicant-dependent. In their 7-day study, Selenastrum capricornutum was the species found to be most efficient at PAH removal/transformation (78\%), while $C$. vulgaris was the least efficient species in removing and transforming PAHs (48\%). All the species under investigation, with the exception of $S$. platydiscus, exhibited higher removal efficiency of fluoranthene than of pyrene. The removal efficiency of fluoranthene and pyrene in a mixture was comparable to or higher than the removal of either compound on its own, suggesting that the presence of one PAH stimulates the removal of the other PAH (Chan et al. 2006; El-Sheekh et al. 2012; Lei et al. 2002; Lei et al. 2007; Safonova et al. 2005).

The batch sorption-kinetics and equilibrium uptake of phenanthrene (PHE), a hydrophobic organic compound (HOC), in aqueous compartments were investigated by Chung et al. (2007), who experimented with dead tissue of the brown seaweed, Sargassum hemiphyllum, under various conditions for $24 \mathrm{hr}$. They found higher shaking rates (50 rpm to $250 \mathrm{rpm})$ and higher temperatures $\left(15^{\circ} \mathrm{C}\right.$ to $\left.35^{\circ} \mathrm{C}\right)$ to be associated with higher sorption rates of PHE, although no significant changes were observed with respect to maximum sorption capacities.

Swackhamer and Skoglund (1993) have noted that the cellulose and lipid content in microalgal cell walls may also have an effect on the biosorption processes because of their strong binding affinity to hydrophobic chemicals. Meanwhile, several studies have been conducted to evaluate the contributions of various fractions of algal detritus on adsorptive removal of organic pollutants 
in order to better understand the interaction between the detritus and the contaminants. As several studies have noted, fatty acids and proteins are the main substances released from dead algal cells under light (Kumar et al. 2019; Ma et al. 2018; Widrig et al. 1996). These findings indicate that some cellular content in dead algal cells is released from broken membranes into the medium and then induces photocatalytic reactions with pollutants (Luo et al. 2014).

In another study, Zhang et al. (2019a) evaluated the adsorption capacity of three PAH compounds (Phe, BaP, and Naph) and reported that, after the removal of the lipid fractions, the adsorption capacity decreased by as much as $25 \%$. This clearly shows that the lipid fractions play an important role in the adsorption of PAHs. Based on their research, polysaccharide might have less effect on adsorption capacity since after its removal, the adsorption capacity of Phe and BaP have been decreased. In contrary, Polysaccharides removal had positive effect on the adsorbtion capacity of Naph and increased the adsorption capacity up to 57\%. Luo et al. (2014) hypothesized that the high adsorption of PAHs by dead cells may be due to the absence of metabolic protection against the transport of pollutants into the cell, increased permeability of the dead cell membrane, and changes to the surface adsorptive properties of the microalgae cell following its death.

Property of pollutants and the removal of algae substances which result in change in composition and structure of algae could be a logical explanation for adsorption. The diffusion of pollutants with lower hydrophobicity was observed after removal of polysaccharides fraction which result in the formation of larger pores on the detritus. Therefore, increase in adsorption capacity of Naph was observed during this process (Zhang et al. 2019a).

Dead Selenastrum capricornutum has been shown to perform well removing phenanthrene, fluoranthene, and pyrene (Chan et al. 2006). One reasonable explanation is that the PHE is removed primarily through a rapid adsorptive removal process, followed by a plant uptake process in the live algae treatments. The principal mechanism involved appears to be physico-chemical adsorption, which is metabolism-independent (Tam et al. 2002). On a related note, Avery et al. (1998) concluded that cell walls provide many potential binding sites for organic and inorganic pollutants, and additional binding sites might become more readily available in dead cells than in 
live cells. Dead algal cells also have a higher capacity for PAH adsorption than do live cells. Table 2-1 shows a summary of different types of biosorbents which have been used for pollutant removal.

Gadd et al. (1990) described an experiment in which, in water treated with dead cells, TBT was rapidly removed in the first $5 \mathrm{~min}$ (e.g., $85 \%$ removal by dead Chlorella cells), but then there was no significant difference in TBT removal between $5 \mathrm{~min}$ and 3 days of treatment. St-Louis et al. (1997) reported that biosorption by Pavlova lutheri occurred almost instantaneously when cells and organotin were mixed (the adsorption of TBT by the exudate coating on the cell wall was in the range of $10 \%$ to $20 \%$ ). 
Table 2-1 Use different types of algae-derived adsorbents in the removal of petroleum pollutants

\begin{tabular}{|c|c|c|c|}
\hline Algae & Compound & Removal rate & Reference \\
\hline $\begin{array}{ll}\text { Spirulina } \quad \text { sp. } & \text { and } \\
\text { Scenedesmus abundans } & \end{array}$ & Diesel and lubricant oil & Up to $75 \%$ & $\begin{array}{l}\text { (Mishra and } \\
\text { Mukherji } \\
\text { 2012) }\end{array}$ \\
\hline E. intestinalis & Crude oil and spent oil & $80 \%$ & $\begin{array}{l}\text { (Boleydei et } \\
\text { al. 2018) }\end{array}$ \\
\hline Sargassum hemiphyllum & Phenanthrene & $91.7-98.4 \%$ & $\begin{array}{l}\text { (Chung et al. } \\
\text { 2007) }\end{array}$ \\
\hline Ulva prolifera & $\begin{array}{l}\text { Benzopyrene, } \\
\text { Naphthalene } \\
\text { Phenanthrene }\end{array}$ & $\mathrm{ND}^{1}$ & $\begin{array}{l}\text { (Zhang et al. } \\
\text { 2019b) }\end{array}$ \\
\hline $\begin{array}{l}\text { Chlamydomonas sp., } \\
\text { Chlorella miniata, Chorella } \\
\text { vulgaris, Scenedesmus } \\
\text { platydiscus, S. quadricauda, } \\
\text { S. Sypricornutum, } \\
\text { Synechosystis sp. }\end{array}$ & Pyrene, Fluoranthene & Up to $78 \%$ & $\begin{array}{l}\text { (Lei et al. } \\
\text { 2002; Lei et } \\
\text { al. 2007) }\end{array}$ \\
\hline $\begin{array}{l}\text { Scenedesmus platydiscus, } \\
\text { Scenedesmus quadricauda } \\
\text { and C. vulgaris }\end{array}$ & PAH & $\mathrm{ND}^{1}$ & $\begin{array}{l}\text { (Luo et al. } \\
2014 \text { ) }\end{array}$ \\
\hline Selenastrum capricornutum & $\begin{array}{l}\text { Phenanthrene, } \\
\text { fluoranthene }\end{array}$ & Up to $90 \%$ & $\begin{array}{l}\text { (Chan et al. } \\
2006)\end{array}$ \\
\hline Ulva prolifera & Phenanthrene & $91.3 \%$ & $\begin{array}{l}\text { (Zhang et al. } \\
\text { 2017) }\end{array}$ \\
\hline${ }^{1}$ Not Determined & & & \\
\hline
\end{tabular}




\subsection{Removal of petroleum pollutants from water using adsorbents derived from fungi, and shells}

Microorganisms play an important role in the fate of organic pollutants in the environment, including through biosorption and biodegradation. The use of bacterial cells as a sorbent to remove aqueous phenanthrene and other organic pollutants has been demonstrated in a number of studies (Díaz 2004; Muñoz et al. 2006; Stringfellow and Alvarez-Cohen 1999); however, the PHE removal achieved in these studies varied ( $42 \%$ to $91 \%$ ). Several studies, meanwhile, have investigated the role of live and heat-killed microbial cells in the adsorption of various pollutants such as NAP, PHE, PYR and crude oil (Rangabhashiyam et al. 2014).

\subsubsection{Removal of oil using adsorbents derived from fungus, bacteria and shells}

The use of the dead cells of microorganisms such as fungi and bacteria as biosorbent has been studied extensively since fungal biomasses are ubiquitous in aquatic environments (Cheng et al. 2020; Wang et al. 2017; Zhou and Kiff 1991). Xu et al. (2013) conducted a study in which, within the experimental time, the surface adsorption of crude oil using live bacterial cells was found to gradually increase likely due to the fact that crude oil is a complex mixture containing $n$-alkanes, aromatics, resins, and asphaltenes, some of which adsorb rapidly on dead cells. However, because of the many polar organic pollutants included and the reversibility of the adsorption occurring in the process, the adsorbed crude oil was released from the dead cells.

Devi et al. (2012) demonstrated that natural biodegradable chitosan of low molecular weight

derived from crab shell can remove most of the colloidal and suspended organic matter in vegetable oil mill effluent. It was observed that the removal efficiency of adsorbent was optimum at a $\mathrm{pH}$ of 4 . They also found that chitosan performs well as an adsorbent due to its efficiency in treating effluent, noting the minimal adsorbent dosage required for the treatment process. Cai et al. (2019) conducted a study to investigate the adsorption kinetics of crab shell-derived biochar with mesoporous structures, finding that it possesses a high capacity to adsorb diesel oil (about $93.9 \mathrm{mg} / \mathrm{g})$. As they noted, this is due to the high specific surface area $\left(2.441 \mathrm{~m}^{2} / \mathrm{g}\right)$, excellent pore 
volume $\left(1.682 \mathrm{~m}^{3} / \mathrm{g}\right)$, and unique surface characteristics present in functional groups such as hydroxyl (-OH-) and carboxyl (-COO-).

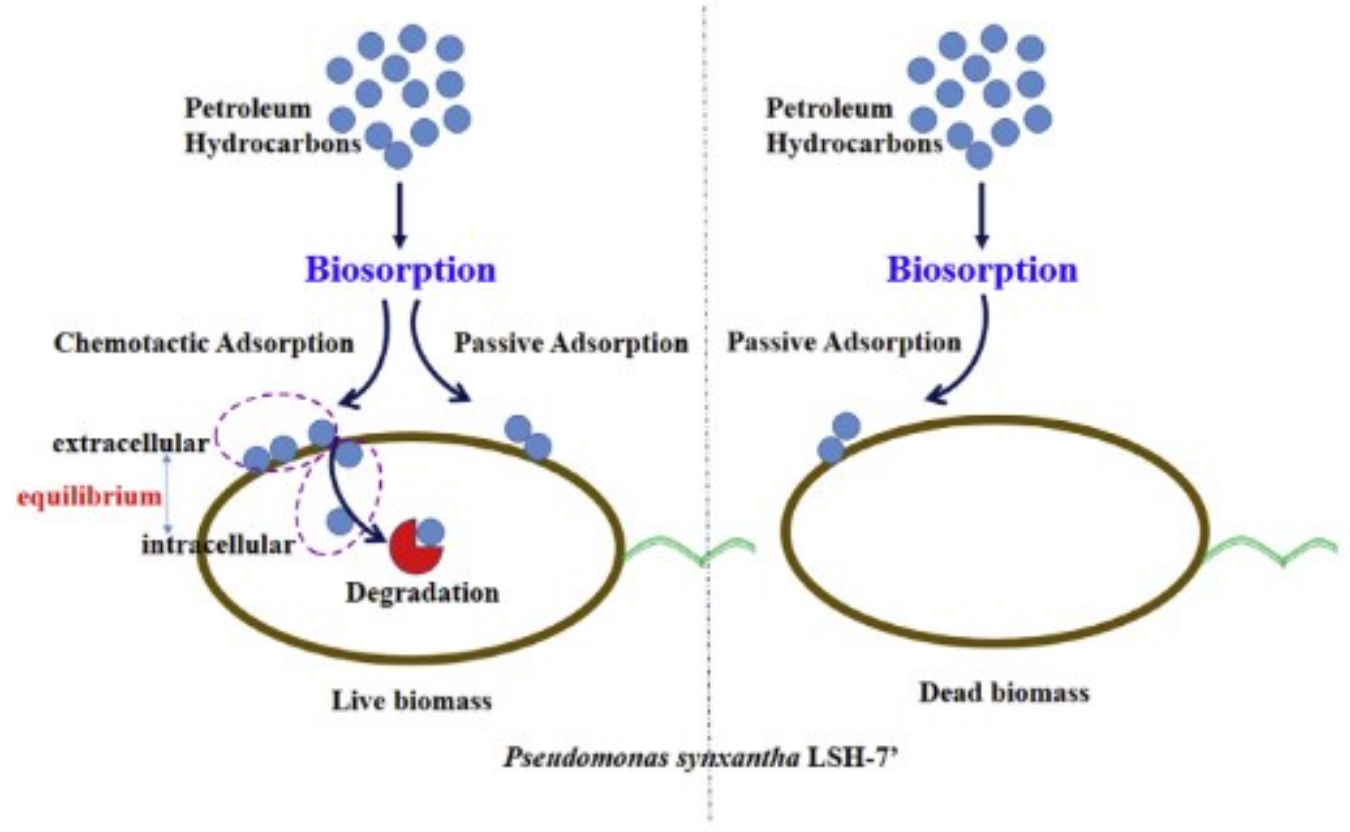

Figure 2-4 Sketch picture of bacterial chemotactic biosorption (Meng et al., 2019)

\subsubsection{Removal of PAHs using adsorbents derived from fungus, bacteria and shells}

Numerous studies have been conducted investigating the transport role in the surface adsorption of different pollutants by dead and live microbial consortia (Tsezos and Bell 1989). As many researchers have noted, the bacterial cell wall acts as the primary component for interacting with pollutants such as metal ions or dyes, where they are sorbed on the surface or within the cell wall (Doyle et al. 1980; Kim et al. 2020; Simelane et al. 2018). Kumar et al. (2008) noted that dead fungal biomasses possess a high capacity for biosorption of toxic pollutants such as heavy metals. Moreover, studies on the biosorption of organic compounds with fungal biomass have shown that enhanced phenolic removal is achieved more efficiently using dead fungal biomass than using a live biosorbent (Rao and Viraraghavan 2002). 
$\mathrm{Xu}$ et al. (2009) explored the adsorption of different substrates by a heat-killed microbial consortium, investigating in particular the role of four different heat-killed bacteria, Pseudomonas sp., Bacillus sp., Ochrobactrum sp., and Pseudomonas sp., in the adsorption over time of petroleum hydrocarbons. The adsorption of PAH compounds achieved by the heat-killed microbial consortium was found to be constant. Due to its high hydrophobicity, PYR was found to be adsorbed more efficiently than PHE and NAP, and this finding is consistent with the results of (Ding et al. 2013). The stability of the surface adsorption of NAP, PHE, PYR, and crude oil by the microbial consortium followed a decreasing order as follows: NAP $>$ PHE $=$ PYR $>$ crude oil. NAP, PHE, and PYR were found to be more easily adsorbed by the microbial consortium than was crude oil up to the 1-minute mark of experimentation, and it was inferred that the process of surface adsorption by a microbial consortium is a rapid process (Xu et al. 2013).

Raghukumar et al. (2006) studied the removal of polycyclic aromatic hydrocarbons from an aqueous culture medium using marine fungus NIOCC \# 312. They attributed the removal disappearance of phenanthrene from the aqueous culture medium to its instant adsorption to the fungal biomass, asserting that heat-killed fungal biomass could be used for the efficient adsorption of PAHs from contaminated sites. Chen et al. (2010) reported the effect of fungal biomass on the biosorption of polycyclic aromatic hydrocarbons in aqueous solutions. They found that the bioadsorption of heat-killed bodies was related to the carbon-normalized partition coefficients and suggested that sorption of organic pollutants in biomass may involve simultaneous surface sorption, partitioning, and chemical reactions.

Both Chen et al. (2010) and Ding et al. (2013) have attributed these phenomena to the bioadsorption behavior of microbial cells with respect to both PAHs and alkane, this, in turn, being governed by the distributional effects of the sorption-desorption process being reversible. The possible mechanisms reported by Chen et al. (2010) that the bioadsorption of heat-killed bodies was relevant with the carbon-normalized partition coefficients. 


\subsection{Major factors which can impact the process}

Many factors, such as the type and nature of the biomass or derived product and freely suspended cells, can affect biosorption. Physical and chemical treatments such as boiling, drying, autoclaving, and mechanical disruption will all also affect the binding properties. For instance, chemical treatments such as alkali treatment often improve biosorption capacity, this being especially evident in some fungal systems because of deacetylation of chitin to form chitosan-glucan complexes with higher metal affinities (Malik et al. 2002; Wang and Chen 2006).

Several parameters such as biomass age, nutrition of the biomass and growth medium can also have effects on biosorption since they change the cell size and wall composition. Another important parameters for each cells and particles are the ratio of surface area to volume area and the available surface area of immobilized biofilms. Also, increasing biomass concentration may have effect on biosorption capacity because it clearly reduces the sorption per unit weight (Chojnacka 2010; de Rome and Gadd 1987). Other physico- chemical factors such as $\mathrm{pH}$, temperature and ion strength are also have an effect on biosorption (Wong-Ng et al. 2018).

\section{(i) $\mathrm{pH}$}

Biosorption in most systems including bacteria, algae and fungi has seen to be $\mathrm{pH}$ - dependent. $\mathrm{pH}$ variation can influence the transfer of oil from sand to the aqueous phase in the presence of microalgal biomass. $\mathrm{pH}$ has complete effect on several factors including competition of sorbate ions and solution chemistry of the adsorbate. It also influences the activity of the functional groups in the biosorbent. Variations in $\mathrm{pH}$ also affect the effectiveness, as the hydrogen ion itself is a tough competing adsorbate (Puranik et al. 1999). Highly alkaline conditions (a pH of 10.0 or higher) have been shown to lead to a decline in biosorption efficiency (Lim et al. 2016). Changes in zeta potentials of oil and algae at different $\mathrm{pH}$ levels also play an important role in oil removal (Lim et al. 2016). Several mechanisms have been proposed for sorption of oil on algae including once the absorption/partitioning of oil on to organic matter and another is adsorption on the surface of algae due to specific interactions. Adsorption which is nonlinear sorption isotherms is a slower phenomenon compared to the absorption/partitioning of HOCs which can be explained by linear isotherm (Al-Shamrani et al. 2002). 


\section{(ii) Temperature}

The effects on biosorption of another environmental parameter, temperature, have also been investigated in a number of studies. Temperature has a vital effect on biosorption process, as increase or decrease in temperature can influence the extent of biosorption (An and Huang 2012). By increasing the surface activity and kinetic energy due to temperature increasing, the removal of pollutants enhances. Contrarily, this may also damage the physical structure of the biosorbent (Park et al. 2010; Pathak et al. 2018). In another study, Rajaković-Ognjanović et al. (2008) found increasing temperature to have a positive effect on oil sorption on algae, as the oil viscosity decreases with increasing temperature. From the microscopic perspective, elevated temperatures are also favorable for enhanced movement of adsorbate molecules from adsorbent. Although increasing temperature is typically favorable to pollutant desorption, though, it should be noted that there could be an increase in the porosity and total pore volume of the biomass adsorbent. In addition, an increase in temperature could result in the swelling of the adsorbent's internal structure and increased penetration of larger oil molecules (Choi and Moreau 1993; Toyoda et al. 2000).

(iii) Ionic strength

Chung et al. (2007) identified a correlation between increased sorption and increased ionic strength. However, Mishra and Mukherji Mishra and Mukherji (2012) noted that the trend in qe variation with ionic strength was significantly affected by the type of algae. They observed, for instance, that the sorption of both lubricating oil and diesel on Spirulina sp. was highest at the lowest ionic strength (background electrolyte, $\mathrm{NaNO}_{3}$, concentration of $0.01 \mathrm{M}$ ), decreased for $\mathrm{NaNO}_{3}$ concentrations of up to $0.1 \mathrm{M}$, then increased significantly at $0.5 \mathrm{M}$ and subsequently decreased again as the $\mathrm{NaNO}_{3}$ concentration was increased to $1 \mathrm{M}$. The sorption of lubricating oil and diesel on $S$. abundans, meanwhile, continuously decreased up to $0.5 \mathrm{M}$ and $0.1 \mathrm{M} \mathrm{NaNO}_{3}$ concentrations, respectively, and subsequently remained invariant as the $\mathrm{NaNO}_{3}$ concentration was increased up to $1 \mathrm{M}$. Chung et al. (2007) reported that maximum sorption of phenanthrene by brown seaweed was attained at low ionic strength, at neutral $\mathrm{pH}$, and at temperatures ranging from $30{ }^{\circ} \mathrm{C}$ to $35{ }^{\circ} \mathrm{C}$. In their study, the expected trend for dissolved organic solute, i.e., an increase in 
sorption with an increase in ionic strength, was not observed for oil sorption on algae. The trend in specific oil/diesel uptake variation with ionic strength, meanwhile, was found to be significantly affected by the type of algae. Beolchini et al. (2006) showed the negative effect of ionic strength on biosorption performance: for instance, the highest determined value for copper-specific uptake was approximately $60 \mathrm{mg} / \mathrm{g}$ at a $\mathrm{pH}$ of 6 and approximately $15 \mathrm{mg} / \mathrm{g}$ at a pH of 4 . 


\section{CHAPTER 3. MATERIALS AND METHOD}

\subsection{Materials}

The microalgal biomass used in this study was derived from $C$. vulgaris and the corresponding powder was obtained from the Organic Traditions (Montreal, Canada). Standard washed and ignited sand (30-40 mesh) was purchased from MilliporeSigma (Oakville, Canada). Crude oil was obtained from Hibernia oil field located in the southeast of St. John's, Newfoundland, Canada. The properties of sand and oil are shown in Table 3-1 and Table 3-2, respectively. Other chemicals were purchased from Sigma-Aldrich (Oakville, Canada).

Table 3-1 Sand specification used in this research

\begin{tabular}{|c|c|}
\hline Specification & Value \\
\hline Particle size form and distribution & Granular, 30 to 40 mesh \\
\hline Formula & $\mathrm{SiO}_{2}$ \\
\hline Color & Beige \\
\hline Molecular Weight (g. mol ${ }^{-1}$ ) & 60.08 \\
\hline Density (g. $\left.\mathrm{cm}^{3}\right)$ & 2.622 at $20^{\circ} \mathrm{C}$ \\
\hline Soluble substances (in $\mathrm{HCl}$ ) & $0.2 \% \max$ \\
\hline
\end{tabular}

Table 3-2 Typical Characterization of crude oil

\begin{tabular}{ll}
\hline Characterization & Value \\
\hline API gravity & 37.1 \\
Density at $20{ }^{\circ} \mathrm{C}\left(\mathrm{g} . \mathrm{mL}^{-1}\right)$ & 0.8370 \\
Dynamic Viscosity at $20^{\circ} \mathrm{C}(\mathrm{cP})$ & 33 \\
Pour point $\left({ }^{\circ} \mathrm{C}\right)$ & 6 \\
Hydrocarbon groups (weight\%) & Saturates (79), aromatics (15), Resins (4), \\
& Asphaltenes (3) \\
\hline
\end{tabular}




\subsection{Experimental procedure}

Batch tests were used to investigate the effect of microalgal biomass on the oil behavior in a sandwater system. A certain amount sand and crude oil was mixed to achieve the initial concentration of $4 \mathrm{~g}$ oil $/ \mathrm{kg}$ sand. The contaminated sand was placed in fume hood for weathering of 7 days. In each test, $0.5 \mathrm{~g}$ of contaminated sand was added into the $20-\mathrm{mL}$ vial. $15 \mathrm{~mL}$ of solution containing various amount of dry weight microalgal biomass was then added into the vial, followed by shaking on a reciprocal shaker at $300 \mathrm{rpm}$ for 24 hours. After that, the aqueous phase in the vial was removed and $15 \mathrm{~mL}$ of hexane was added into the vial followed by shaking for 24 hours to extract the remaining oil from sand. Different biomass dose, $\mathrm{pH}$, temperature, and salinity levels were used in these tests. Solution $\mathrm{pH}$ was adjusted with $1 \mathrm{M} \mathrm{NaOH}$ or $\mathrm{HCl}$. The vials with water in the absence of microalgal biomass were used as the controls. All the tests were conducted in triplicate and the mean values were used in data analysis.

\subsection{Factorial design}

To further evaluate the effects of environmental conditions on oil behavior, a $2^{4}$ full factorial design was employed. Four factors including microalgal biomass dose, solution $\mathrm{pH}$, temperature, and salinity were considered with the response of remaining oil $\left(\mathrm{mg} \mathrm{kg}^{-1}\right)$. All factors were studied at two levels. The low and high levels were coded as -1 and +1 , respectively Table 3-3. 48 runs of experiments were conducted and the details are shown in Table 3-4. Minitab 15 statistical software (Minitab Inc., State College, USA) was used to design experiments and analyze the experimental data. 
Table 3-3 Coded and uncoded values of the factors.

\begin{tabular}{lllll}
\hline \multirow{2}{*}{ Symbol } & Factor & Units & \multicolumn{2}{c}{ Level } \\
\cline { 5 - 5 } & & & Low $(-1)$ & High $(+1)$ \\
\hline A & A & ppm & 500 & 5000 \\
B & $\mathrm{pH}$ & & 5 & 9 \\
$\mathrm{C}$ & Temperature & & & 20 \\
$\mathrm{D}$ & Salinity & $\%$ & 10 & 3.5 \\
\hline
\end{tabular}


Table 3-4 Coded levels and corresponding values for factorial design matrix.

\begin{tabular}{|c|c|c|c|c|c|c|c|c|}
\hline \multirow{2}{*}{$\begin{array}{l}\text { Run } \\
\text { Number }\end{array}$} & \multirow[b]{2}{*}{ A } & \multicolumn{3}{|c|}{ Coded levels } & \multirow{2}{*}{$\begin{array}{l}\text { A } \\
\text { Biomass Dose } \\
(\mathrm{ppm})\end{array}$} & \multirow{2}{*}{$\frac{\mathrm{B}}{\mathrm{pH}}$} & \multirow{2}{*}{$\begin{array}{l}\mathrm{C} \\
\text { Temperature } \\
{ }^{\circ} \mathrm{C}\end{array}$} & \multirow{2}{*}{$\begin{array}{l}\mathrm{D} \\
\text { Salinity } \\
(\%)\end{array}$} \\
\hline & & B & $\mathrm{C}$ & $\mathrm{D}$ & & & & \\
\hline 1 & -1 & -1 & -1 & -1 & 500 & 5 & 10 & 1 \\
\hline 2 & -1 & 1 & -1 & -1 & 500 & 9 & 10 & 1 \\
\hline 3 & -1 & -1 & -1 & 1 & 500 & 5 & 10 & 3.5 \\
\hline 4 & -1 & 1 & -1 & 1 & 500 & 9 & 10 & 3.5 \\
\hline 5 & 1 & -1 & -1 & -1 & 5000 & 5 & 10 & 1 \\
\hline 6 & -1 & 1 & 1 & -1 & 500 & 9 & 10 & 1 \\
\hline 7 & 1 & -1 & -1 & 1 & 5000 & 5 & 10 & 3.5 \\
\hline 8 & 1 & 1 & -1 & 1 & 5000 & 9 & 10 & 3.5 \\
\hline 9 & -1 & -1 & 1 & -1 & 500 & 5 & 20 & 1 \\
\hline 10 & -1 & 1 & 1 & -1 & 500 & 9 & 20 & 1 \\
\hline 11 & -1 & -1 & 1 & 1 & 500 & 5 & 20 & 3.5 \\
\hline 12 & -1 & 1 & 1 & 1 & 500 & 9 & 20 & 3.5 \\
\hline 13 & 1 & -1 & 1 & -1 & 5000 & 5 & 20 & 1 \\
\hline 14 & 1 & 1 & 1 & -1 & 5000 & 9 & 20 & 1 \\
\hline 15 & 1 & -1 & 1 & 1 & 5000 & 5 & 20 & 3.5 \\
\hline 16 & 1 & 1 & 1 & 1 & 5000 & 9 & 20 & 3.5 \\
\hline 17 & -1 & -1 & -1 & -1 & 500 & 5 & 10 & 1 \\
\hline 18 & -1 & 1 & -1 & -1 & 500 & 9 & 10 & 1 \\
\hline 19 & -1 & -1 & -1 & 1 & 500 & 5 & 10 & 3.5 \\
\hline 20 & -1 & 1 & -1 & 1 & 500 & 9 & 10 & 3.5 \\
\hline 21 & 1 & -1 & -1 & -1 & 5000 & 5 & 10 & 1 \\
\hline 22 & -1 & 1 & 1 & -1 & 500 & 9 & 10 & 1 \\
\hline 23 & 1 & -1 & -1 & 1 & 5000 & 5 & 10 & 3.5 \\
\hline 24 & 1 & 1 & -1 & 1 & 5000 & 9 & 10 & 3.5 \\
\hline
\end{tabular}




\begin{tabular}{|c|c|c|c|c|c|c|c|c|}
\hline 25 & -1 & -1 & 1 & -1 & 500 & 5 & 20 & 1 \\
\hline 26 & -1 & 1 & 1 & -1 & 500 & 9 & 20 & 1 \\
\hline 27 & -1 & -1 & 1 & 1 & 500 & 5 & 20 & 3.5 \\
\hline 28 & -1 & 1 & 1 & 1 & 500 & 9 & 20 & 3.5 \\
\hline 29 & 1 & -1 & 1 & -1 & 5000 & 5 & 20 & 1 \\
\hline 30 & 1 & 1 & 1 & -1 & 5000 & 9 & 20 & 1 \\
\hline 31 & 1 & -1 & 1 & 1 & 5000 & 5 & 20 & 3.5 \\
\hline 32 & 1 & 1 & 1 & 1 & 5000 & 9 & 20 & 3.5 \\
\hline 33 & -1 & -1 & -1 & -1 & 500 & 5 & 10 & 1 \\
\hline 34 & -1 & 1 & -1 & -1 & 500 & 9 & 10 & 1 \\
\hline 35 & -1 & -1 & -1 & 1 & 500 & 5 & 10 & 3.5 \\
\hline 36 & -1 & 1 & -1 & 1 & 500 & 9 & 10 & 3.5 \\
\hline 37 & 1 & -1 & -1 & -1 & 5000 & 5 & 10 & 1 \\
\hline 38 & -1 & 1 & 1 & -1 & 500 & 9 & 10 & 1 \\
\hline 39 & 1 & -1 & -1 & 1 & 5000 & 5 & 10 & 3.5 \\
\hline 40 & 1 & 1 & -1 & 1 & 5000 & 9 & 10 & 3.5 \\
\hline 41 & -1 & -1 & 1 & -1 & 500 & 5 & 20 & 1 \\
\hline 42 & -1 & 1 & 1 & -1 & 500 & 9 & 20 & 1 \\
\hline 43 & -1 & -1 & 1 & 1 & 500 & 5 & 20 & 3.5 \\
\hline 44 & -1 & 1 & 1 & 1 & 500 & 9 & 20 & 3.5 \\
\hline 45 & 1 & -1 & 1 & -1 & 5000 & 5 & 20 & 1 \\
\hline 46 & 1 & 1 & 1 & -1 & 5000 & 9 & 20 & 1 \\
\hline 47 & 1 & -1 & 1 & 1 & 5000 & 5 & 20 & 3.5 \\
\hline 48 & 1 & 1 & 1 & 1 & 5000 & 9 & 20 & 3.5 \\
\hline
\end{tabular}




\subsection{Analytical methods}

The oil concentration in hexane was measured by a Thermo Scientifi Evolution 201 UV-Visible spectrophotometer (MA, USA) with wavelength of $220 \mathrm{~nm}$. A Jenway $3310 \mathrm{pH}$ meter (Jenway Ltd., UK) was used to determine the $\mathrm{pH}$ of solution. The IR spectra of crude oil, algae, and algae with crude oil were recorded in triplicate using a Tensor 27 FTIR-ATR Spectrometer (Bruker, USA).

Fourier-transform infrared spectroscopy (FTIR) is a technique used to obtain an infrared spectrum of absorption or emission of a solid, liquid or gas. An FTIR spectrometer simultaneously collects high-spectral-resolution data over a wide spectral range. This confers a significant advantage over a dispersive spectrometer, which measures intensity over a narrow range of wavelengths at a time. FTIR can be used in all applications where a dispersive spectrometer was used in the past. In addition, the improved sensitivity and speed have opened up new areas of application. Spectra can be measured in situations where very little energy reaches the detector and scan rates can exceed 50 spectra a second. Fourier transform infrared spectroscopy is used in geology, chemistry, materials and biology research fields. Fourier transform infrared (FTIR) spectroscopy has been widely used in the analysis of oil (Deivakumari et al. 2020; Xin et al. 2019b). It can generate unique spectral signatures related to the absorption pattern of crude oil with the major bands (Hadjoudja et al. 2010). Asemani and Rabbani (2020) studied FTIR spectroscopy characterization of crude oil extracted asphaltenes. In their study, four oil samples were collected from different oil fields and Asphaltene extraction from crude oil samples was analyzed using FTIR. In another study which was conducted by Riley et al. (2016), ten different oil samples from various geographical regions were collected and the fractions of the crude and heavy fuel oils were analysed on a Perkin Elmer Spectrum 400 FTIR/FT-NIR Spectrometer (Perkin Elmer, Australia). Kök et al. (2017) also conducted crude oil characterization using FTIR during their study on four different origin crude oil samples. The use of Fourier transform infrared (FTIR) spectroscopy in algal biomass analysis has also been reported in monitoring biochemical changes (Ibrahim et al. 2010). Xin et al. (2018) conducted a research about the toxicity of triclosan to green microalga chlorococcum $s p$. In their study, FTIR was used to determine the characterization of algae. 
The functional groups involved in oil sorption can be identified via the determination of the chemical structure of sorbents before and after oil sorption (Boleydei et al. 2018; Cheu et al. 2016). Sorption has been correlated with the type of functional groups present on the algal cell wall as determined through FTIR studies Mishra and Mukherji (2012). In the present study, to better understand the interaction and identify the functional groups involved during the contact between oil and algae, the oil was mixed with microalgal powder and FTIR analysis was conducted to determine the chemical structure of microalgal biomass ( $C$-vulgaris) before and after sorption of oil. ATR-FTIR spectroscopy generated unique spectral signatures related to the absorption pattern of crude oil with the major bands.

Samples were placed on to the diamond radiation area of the ATR device. Each spectrum was an average of 128 scans in the 4000 to $400 \mathrm{~cm}^{-1}$ spectral range, using transmission mode for crude oil and reflection mode for algae samples with a resolution of $4 \mathrm{~cm}^{-1}$. The spectra were collected and processed using OPUS 7.2 software (Bruker, USA). FTIR spectromicroscopy was conducted to image single microalgal cell with or without crude oil on beamline 01B1-01(MidIR) at CLS. A Bruker Vertex 70v interferometer coupled to a Hyperion 3000 IR confocal microscope with a 15× objective was applied to acquire the images using a Globar (Xin et al. 2019a). Spectral images were acquired using reflection mode for algae samples with a resolution of $4 \mathrm{~cm}^{-1}$. Each spectrum was an average of 128 scans, using a $64 \times 64$ pixel mid-infrared FPA detector. Three repeats for each sample were conducted using OPUS 7.2 software and the images were generated using CytoSpec 2.00.01 software (Cytpspec Inc., USA). The surface morphology of algae biomass was measured by Quanta 400 scanning electron microscope (FEI, USA). Meanwhile, the elemental constituents were also analyzed by SEM-EDS. The particle size of microalgal biomass was determined by Mastersizer 3000 laser diffraction system equipped with Hydro EV exchangeable volume wet sample dispersion unit (Malvern Instruments, USA).

\subsection{Quality assurance/quality control}

The quality assurance/quality control program was followed to ensure the accuracy and reliability of the collected data. All batch tests were conducted in triplicate and average values were reported 
(relative standard deviation less than 5\%). Blank tests were run and corrections were applied if necessary. All containers used in this study has been previously cleaned with the particular washing liquid for laboratory purposes, triply rinsed with distilled water and oven dried. For each experimental run, oil contaminated sand and deionized water was used without addition of any algal powder. The corresponding results confirmed that the initial concentration of solution including contaminated sand remained unchanged during the experiment. It indicated that the reduction of oil concentration in contaminated sand during adsorption tests was only related to the presence of algal biomass. Statistical calculations and analyses were performed with the use of the Minitab (Minitab Inc., USA) statistical software package. 


\section{CHAPTER 4. RESULTS AND DISCUSSION}

\subsection{Characterization of microalgal biomass interacted with oil}

Chlorella is a group of eukaryotic green microalgae with a high capacity for photosynthesis and growth (Nigam and Singh 2011). These microalgae have simple life cycles and metabolic pathways similar to higher plants. Therefore, they have been employed as indicator organisms for research on the mechanisms of photosynthesis and assimilation of carbon dioxide (Nabavi and Silva 2018). Figure 4-1(A) shows the SEM images of $C$. vulgaris biomass. C. vulgaris is a spherical microscopic cell with 2-10 $\mu \mathrm{m}$ diameter and it shares many structural elements similar to plants. The rigidity preserves the integrity of the cell and is basically a protection against invaders and harsh environment. It may vary according to each growth phase (Safi et al. 2014). As a natural biomass, the algae cells are mainly composed of many organic matters. According to the EDS results shown in Figure 4-1(B), the amounts of $\mathrm{C}, \mathrm{O}, \mathrm{P}$ and $\mathrm{S}$ of microalgal biomass were 35.9, 40.6, 0.3 and $0.2 \%$, respectively. Hao et al. (Hao et al. 2017) conducted the elemental analysis for this strain and got the similar results of $46.67 \% \mathrm{C}, 6.92 \% \mathrm{H}$, and $37.97 \% \mathrm{O}$. Some mineral elements such $\mathrm{Si}, \mathrm{Na}, \mathrm{Cu}$ and $\mathrm{Ca}$ were also observed in this microalgal biomass. Figure 4-1(C) depicts the particle size distribution of algal biomass. It can be seen that $10 \%$ of the microalgal particles had a diameter less than $30.2 \mu \mathrm{m}$ and $50 \%$ of the particles had a diameter less than $64.8 \mu \mathrm{m}$. Almost $90 \%$ of the microalgal particles were with the diameter less than $121 \mu \mathrm{m}$. Microalgae particle size is smaller than macroalgae. Such a small size of microalgae let them move easily with current and waves, and they can also enter on the void space of beaches. 

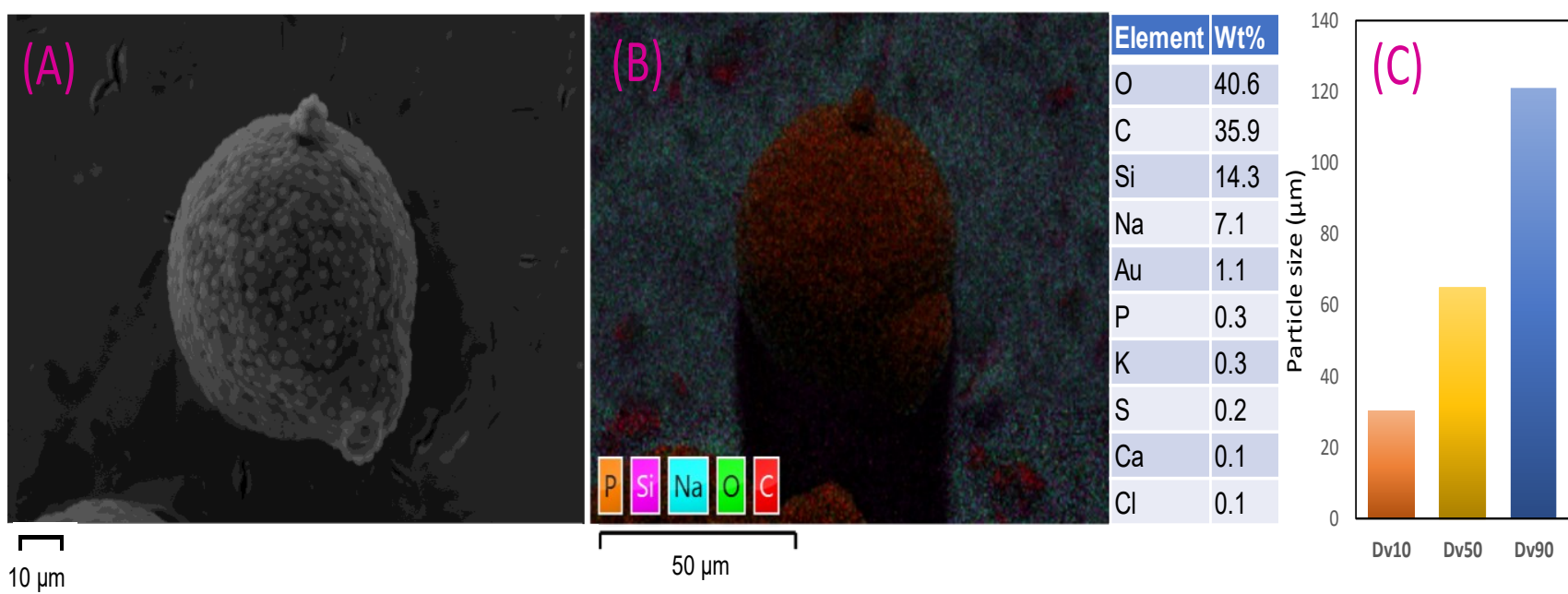

Figure 4-1 (A) SEM image of C. vulgaris cell, (B) Energy Dispersive X-Ray Spectroscopy (EDS) of C. vulgaris cell, (C) Particle size analysis of C. vulgaris biomass

As microalgal biomass in solution contacted with oil-contaminated sand, there would be an interaction between oil and microalgal biomass. To better understand such interaction and identify the functional groups involved during the contact between oil and algae, the oil was mixed with microalgal powder and FTIR analysis was conducted to determine the chemical structure of microalgal biomass (C-vulgaris) before and after sorption of oil. ATR-FTIR spectroscopy generated unique spectral signatures related to the absorption pattern of crude oil with the major bands shown in Table 4-1. Comparing to algae, ATR-FTIR spectra of algae with crude oil presented spectral signatures of crude oil (Figure 4-2(A)). For algae with crude oil, the infrared spectra at 2952, 2920 and $2853 \mathrm{~cm}^{-1}$ were more intensive than that of algae, resulting from the contribution of the stretching aliphatic bands $(\mathrm{v}-(\mathrm{CH} 3+\mathrm{CH} 2))$ from crude oil. Similarly, there were also more intensive bands at 1459 and $1377 \mathrm{~cm}^{-1}$, corresponding to the deformation bands of methyl and methylene groups from crude oil. A new band appeared at $1708 \mathrm{~cm}^{-1}$ was attributed to carbonyl and/or carboxyl groups $(\mathrm{v}-(\mathrm{C}=\mathrm{O}))$, observed in crude oil spectra but not in algae spectra. In the region $800-900 \mathrm{~cm}^{-1}$, two bands occurred at 810 and $870 \mathrm{~cm}^{-1}$ which could be assigned to the outof-plane deformation vibration of $\mathrm{C}-\mathrm{H}$ bond $(\gamma(\mathrm{CHar}))$ of aromatic ring from crude oil. Comparing with algae, the occurrence of a new peak and the increases of many other band peaks in the infrared 
spectra of algae with crude oil was attributed to the sorption of crude oil onto algae. The most distinguishable spectra peaks include aliphatic hydrocarbons, carbonyls and aromatics. FTIR spectromicroscopic imaging can also provide a straightforward evidence that crude oil could be sorbed by algae. As shown in (Figure 4-2 (B2-F2)), single mircoalgal cell with oil had more intensive signal in the spatial distribution of main functional groups, such as aliphatic hydrocarbons, carbonyls and aromatics from crude oil, compared with mircoalgal cell without oil (B1 - F1). The band centered at $1708 \mathrm{~cm}^{-1}$ was integrated and newly occurred in algae sample with crude oil. This was attributed to the sorption of crude oil, which is consistent with infrared spectra results. The integrated groups were distributed evenly around the cell, indicating the distribution of sorbed crude oil was homogeneous. Since algae powder used in this study didn't include living algae, it is likely that crude oil was unable to enter into cells but could be sorbed around mircoalgal cell surface. Moreover, the intensified color presented the sorption amount of crude oil was substantial. Therefore, there could be an interaction between algae and oil once they contacted.

Table 4-1 Wavenumber $\left(\mathrm{cm}^{-1}\right)$ and assignment of the major bands of ATR-FTIR spectra of crude

\begin{tabular}{ll} 
Wavenumber $\left(\mathrm{cm}^{-1}\right)$ & Vibrational mode assignment and main contribution \\
\hline $2952,2920,2853$ & stretching aliphatic bands $\left(\mathrm{v}\left(\mathrm{CH}_{3}+\mathrm{CH}_{2}\right)\right)$ \\
1708 & carbonyl and/or carboxyl groups $(\mathrm{v}-(\mathrm{C}=\mathrm{O})$ \\
1459 & deformation bands of methyl and methylene groups $(\delta-(\mathrm{CH} 3+\mathrm{CH} 2))$. \\
1377 & deformation bands of methyl $\left(1365 \mathrm{~cm}^{-1}\right)$ \\
870,810 & out-of plane deformation vibration of aromatic $\mathrm{C}-\mathrm{H}$ bond
\end{tabular}



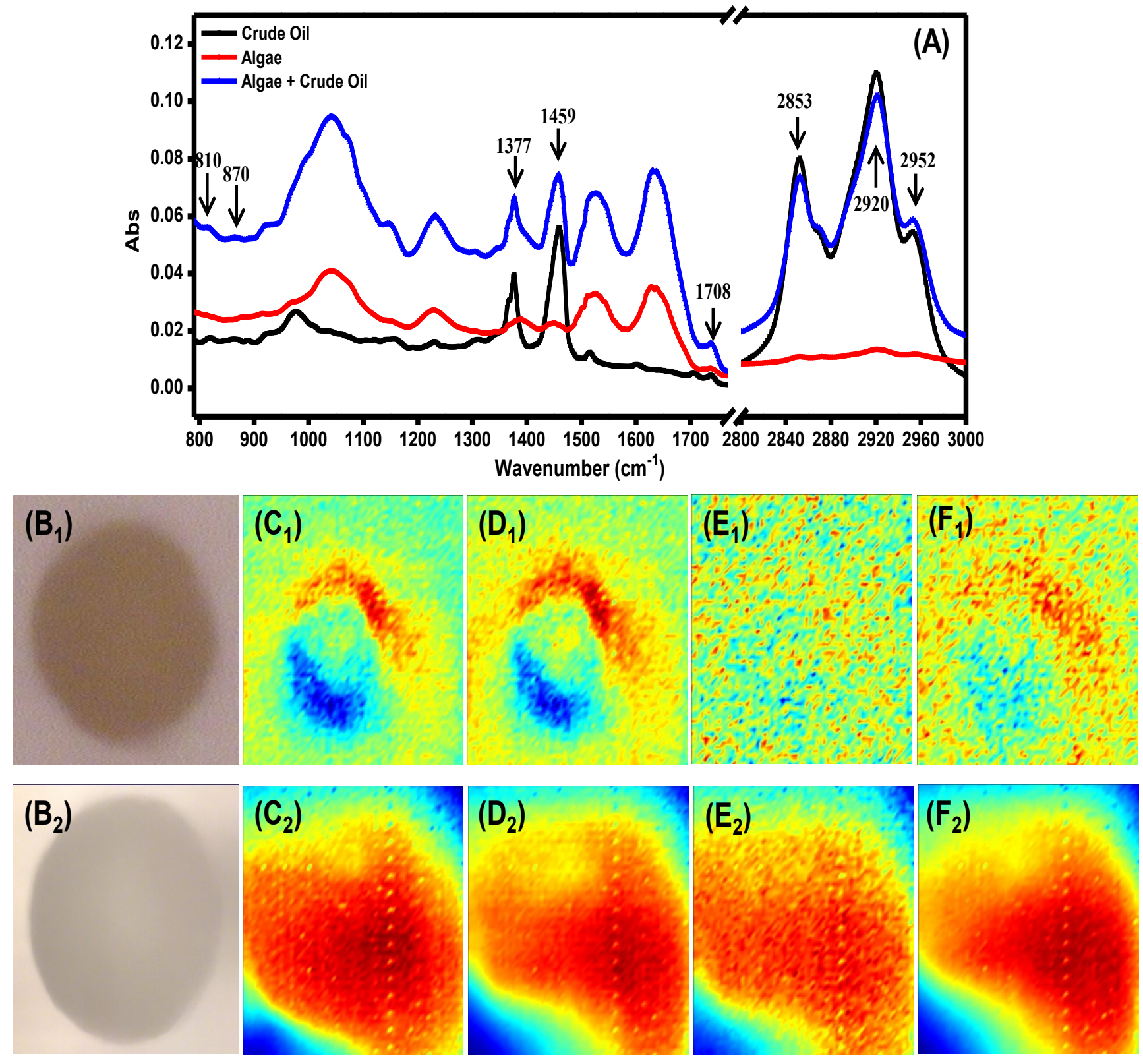

Figure 4-2 ATR-FTIR spectra for crude oil, algae, and crude oil * algae (A). Microscopic imaging (B1, B2) and FTIR spectromicroscopic imaging for samples of algae, and crude oil * algae at 3001-2765 $\mathrm{cm}^{-1}(\mathrm{C} 1, \mathrm{C} 2), 1490-1326 \mathrm{~cm}^{-1}(\mathrm{D} 1, \mathrm{D} 2), 1721-1694 \mathrm{~cm}^{-1}(\mathrm{E} 1, \mathrm{E} 2)$ 


\subsection{Effect of microalgal biomass dose on oil behavior}

The impact of microalgal biomass dose ranging from 0.01 to $8 \mathrm{~g} \mathrm{~L}^{-1}$ on oiled sand was studied with the $\mathrm{pH}$ of 7 , temperature of $20{ }^{\circ} \mathrm{C}$ and salinity of $0 \%$. The results are shown in Figure 4-3. It can be found that when the dose of microalgal biomass increased, the amount of remaining oil on sand decreased. It took about $5 \mathrm{~g} \mathrm{~L}^{-1}$ of mircoalgal powder to reduce residual oil concentration to $1065 \mathrm{mg} \mathrm{kg}^{-1}$. This decrease of remaining oil on sand tended to be stable when the microalgal biomass dose was higher than $5 \mathrm{~g} \mathrm{~L}^{-1}$. It was reported that the adsorption of oil increased as biomass concentration changed from 0.01 to $8 \mathrm{~g} \mathrm{~L}^{-1}$ (Boleydei et al. 2018). In this sand-water system, the microalgal biomass could be bound with oil. The surface area of mircoalgal powder was high due to the small particle size (Chojnacka et al. 2005). There were also many micropores on algal powder (Ibrahim et al. 2010). The increase of microalgal biomass dose provided more functional groups such as aliphatic bands in algal cells and active sites for the binging of oil. The biomass powder could also act as the bridge for binding oil in liquid (Ahmad et al. 2005b). Nwokoma and Anene (2010) found also reported that algal particles less than $150 \mu \mathrm{m}$ presented the highest removal of oil from water with short time reaching equilibrium. In addition, there was an equilibrium between the oil in water and the oil on sand surface. Once the oil droplets in water were adsorbed on microalgal powder, it would facilitate the shifting of equilibrium and resulting more desorbed oil from sand. The shallow and nutrient-rich water in the coastal area provides an ideal place for the growth of algae. The algal biomass amount can even reach a very high level when there is an algae bloom. Such impact of algal biomass amount should be taken into consideration for the evaluation of oil behaviors on oiled shoreline. 


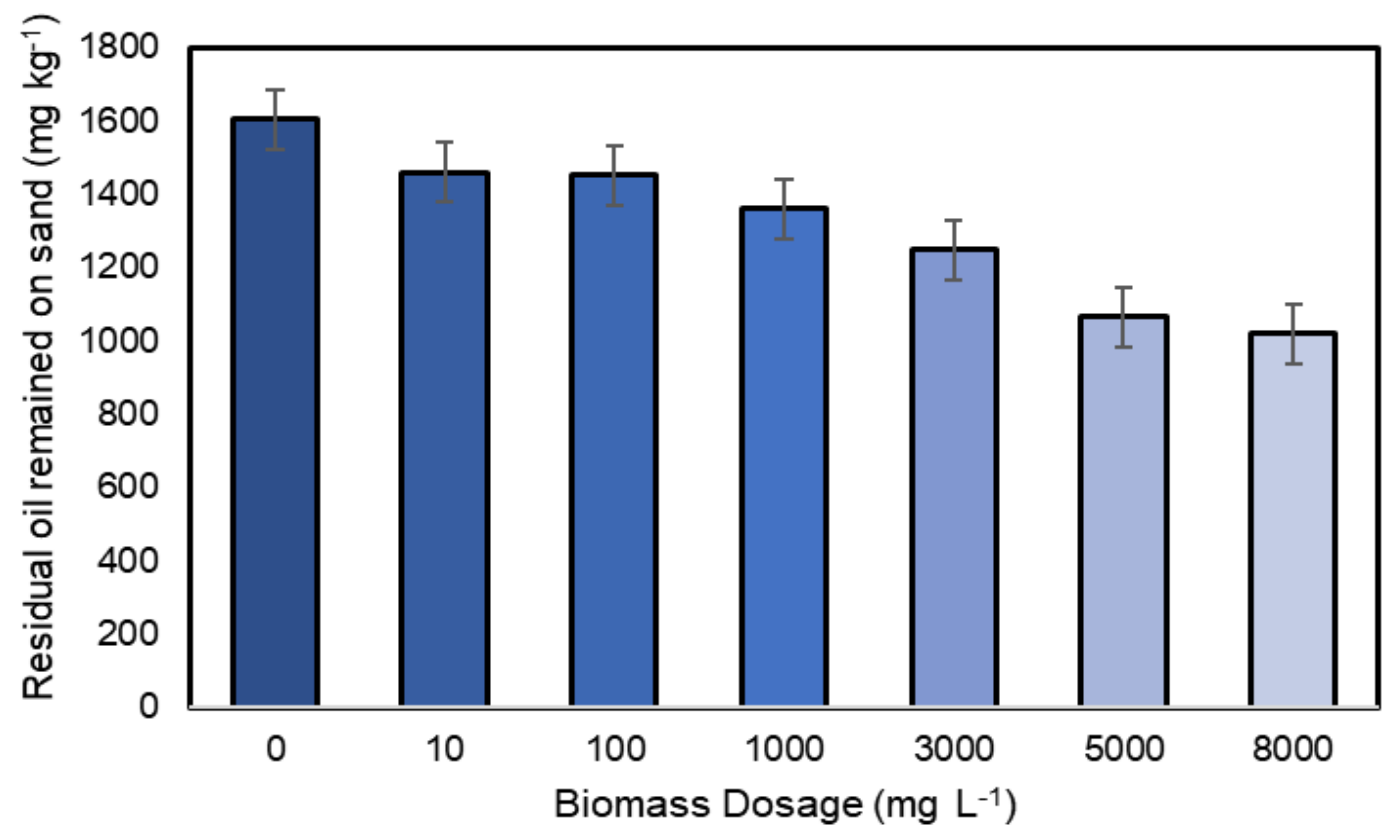

Figure 4-3 The effect of biomass dose on the oil behavior in a sand-water system.

\subsection{Effect of $\mathrm{pH}$ on oil behavior}

Although, The $\mathrm{pH}$ of solution is an important parameter which can affect the pollutant transport and binding (Ibrahim et al. 2010; Zhao et al. 2019). $\mathrm{pH}$ in seawater and shoreline sediments may vary considerably in the environment (Cleary et al. 2018). In order to explore the effect of $\mathrm{pH}$ on oil behavior in the presence of microalgal biomass, the tests were conducted in the $\mathrm{pH}$ range of 410 with the microalgal biomass dose of $5000 \mathrm{ppm}$, temperature of $20{ }^{\circ} \mathrm{C}$ and salinity of $0 \%$, and the results are shown in Figure 4-4. The remaining oil decreased with increasing solution $\mathrm{pH}$ to 7 and an increase of remaining oil was observed when the $\mathrm{pH}$ was further increased above 7. The results indicate that $\mathrm{pH}$ variation could influence the transfer of oil from sand to aqueous phase in the presence of microalgal biomass. The changes in zeta potentials of sand, oil and algae at different $\mathrm{pH}$ levels played an important role in this process. It was reported that both sand particles and oil droplets were with negative charge regardless of $\mathrm{pH}$ levels (Lim et al. 2016). As $\mathrm{pH}$ increased from 4 to 7 , there could be increased differential surface charge between sand particles and oil droplets (Lim et al. 2016), resulting the higher repulsion between sand and oil and less oil 
remained in sand. The binding of oil onto biomass including algae has been observed (Boleydei et al. 2018; Mishra and Mukherji 2012). The oil removed from sand could be adsorbed by microalgal biomass, with the relatively stable surface charge was in this $\mathrm{pH}$ range. Therefore, the overall conditions were favorable for the increased oil removal and less oil remained on sand. As pH further increased above 7, an increase of remained oil on sand was observed. On the one hand, the oil could become less negative at high $\mathrm{pH}$ (Al-Shamrani et al. 2002). That would be favorable for the binding between oil and sand. On the other hand, the algae surface could also become more negative at high $\mathrm{pH}$ (Malik et al. 2002). Such conditions would thus facilitate the oil binding to sand and less adsorption of oil on microalgal biomass in this sand-water system.

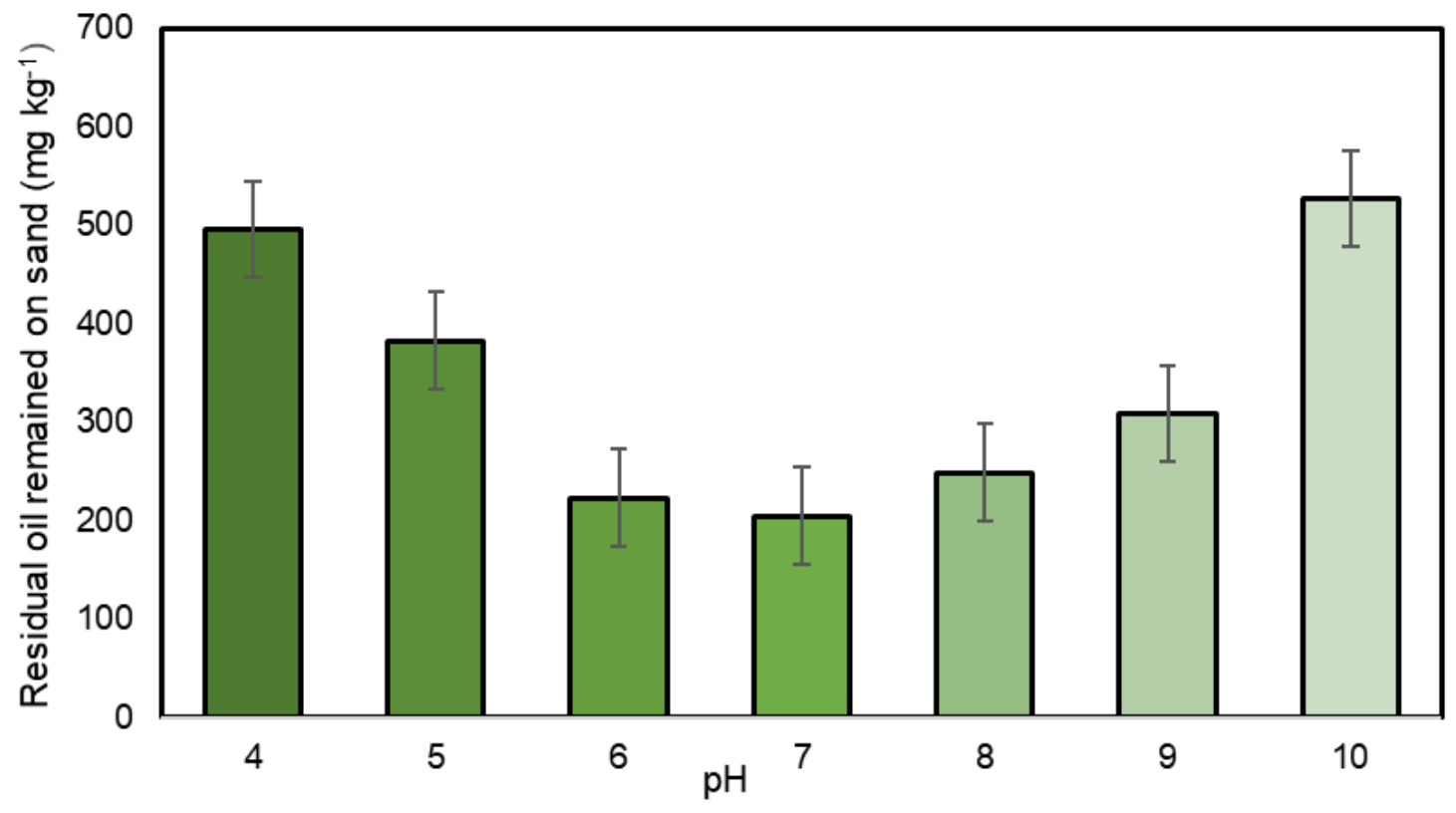

Figure 4-4 The effect of $\mathrm{pH}$ on the oil behavior in a sand-water system 


\subsection{Effect of temperature on oil behavior}

The temperatures of near-surface sea and shoreline vary with latitude in response to incoming solar radiation and outgoing longwave radiation. The temperature can range from $30^{\circ} \mathrm{C}$ at the tropical region to $-1{ }^{\circ} \mathrm{C}\left(30.2{ }^{\circ} \mathrm{F}\right)$ at the arctic region. The effect of temperature on oil behavior in the presence of algal by mircoalgal biomass was studied at different temperatures from 5 to $30{ }^{\circ} \mathrm{C}$ with the microalgal biomass dose of $5000 \mathrm{ppm}, \mathrm{pH}$ of 7 and salinity of $0 \%$. As shown in Figure 4-5, the oil remained on sand in the presence of microalgal biomass decreased as temperature increased. The remaining oil on sand was $636.9 \mathrm{mg} \mathrm{kg}^{-1}$ at $5{ }^{\circ} \mathrm{C}$, while it decreased to $222.9 \mathrm{mg} \mathrm{kg}^{-1}$ at 25 ${ }^{\circ} \mathrm{C}$. Temperature is as an important parameter that can often affect pollutant behavior (An and Huang 2012). The oil viscosity would decrease with the increasing temperature. The lower viscosity at high temperature could facilitate the oil removal from oiled sand to liquid phase. From the microscopic view, the elevated temperatures are also favorable for enhanced movement of adsorbate molecules from adsorbent (Rajaković-Ognjanović et al. 2008). Once oil left from sand into solution, oil was further bound with microalgal biomass. Although increasing temperature was usually favorable to the pollutant desorption, there could be an increase in the porosity and total pore volume of biomass adsorbent. In addition, the increase in temperature could result in the swelling of adsorbent internal structure and increased penetration of larger oil molecules. Similar results were also observed in previous studies about the adsorption of oil on nonwovens cotton and exfoliated graphite (Choi and Moreau 1993; Toyoda et al. 2000) Therefore, the overall effects of these processes let to the decreased remaining oil as temperature increased. 


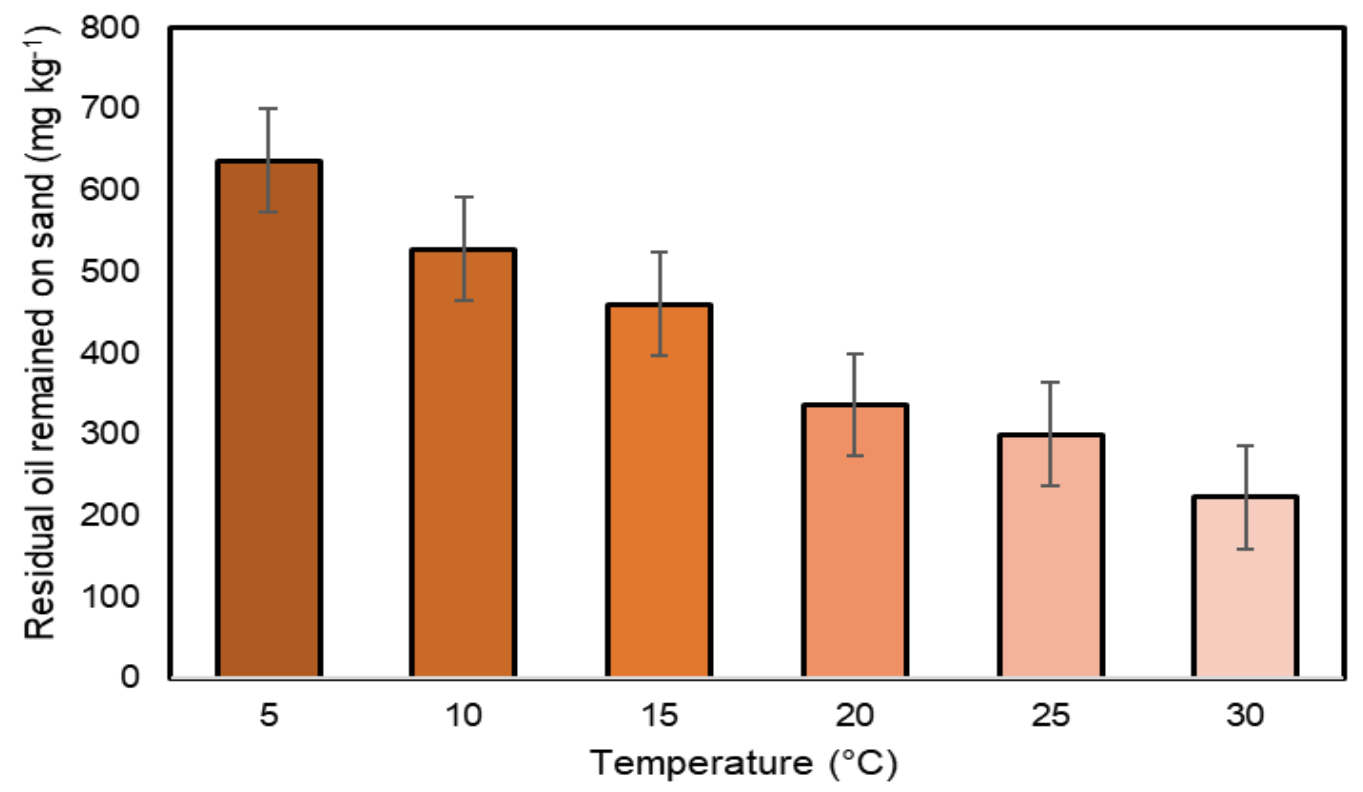

Figure 4-5 The effect of temperature on oil behavior in a sand-water system

\subsection{Effect of salinity on oil behavior}

The average salinity of the sea water typically varies from $3.2 \%$ to $3.7 \%$. It may be less than $3 \%$ in polar regions. The departure from a mean salinity of approximately $3.5 \%$ is usually caused by processes at Earth's surface that locally add or remove fresh water. In the region of the ocean receiving the fresh water such as estuaries, the salinity may be lowered by dilution. The effect of salinity on oil removal in the presence of microalgal biomass was investigated in this study and four different salinity levels up to $4.5 \%$ were evaluated with the microalgal biomass dose of 5000 ppm, $\mathrm{pH}$ of 7, and temperature of $20^{\circ} \mathrm{C}$. As shown in Figure 4-6, the changing salinity can affect the oil behavior in this system. Increasing the salinity level from 0 to $3.5 \%$ resulted in decreasing remained oil in sand from 205 to $82 \mathrm{mg} \mathrm{kg}^{-1}$ correspondingly. The algae cells and oil droplets is usually negatively charged. Adding sea salt including positive ion like $\mathrm{Na}^{+}$could affected the surface charge of biomass. As the salinity increased, there would be a compressed electric double layer, making it easier for particles to approach each other and form oil particle aggregates (Le Floch et al. 2002). It was reported there was no noticeable change of surface charge of oil droplets as salt concentration increased (Liu et al. 2007). However, increasing salinity could increase the 
surface charge of biomass powder (Lin et al. 2003). As the salinity increased, the favorable oil adsorption by algae would result in the decreased oil remained on sand. When the salinity further changed to $4.5 \%$, the residual oil on sand increased to $100.59 \mathrm{mg} \mathrm{kg}^{-1}$. The solubility of oil decreased due to the salting-out effect at high salinity, which could facilitate the sorption of oil on sand. In addition, the high salinity was correlated with the smaller algae surface area (REED et al. 1980). That would limit the combination of oil and microalgal biomass and thus left more oil on sand and in water.

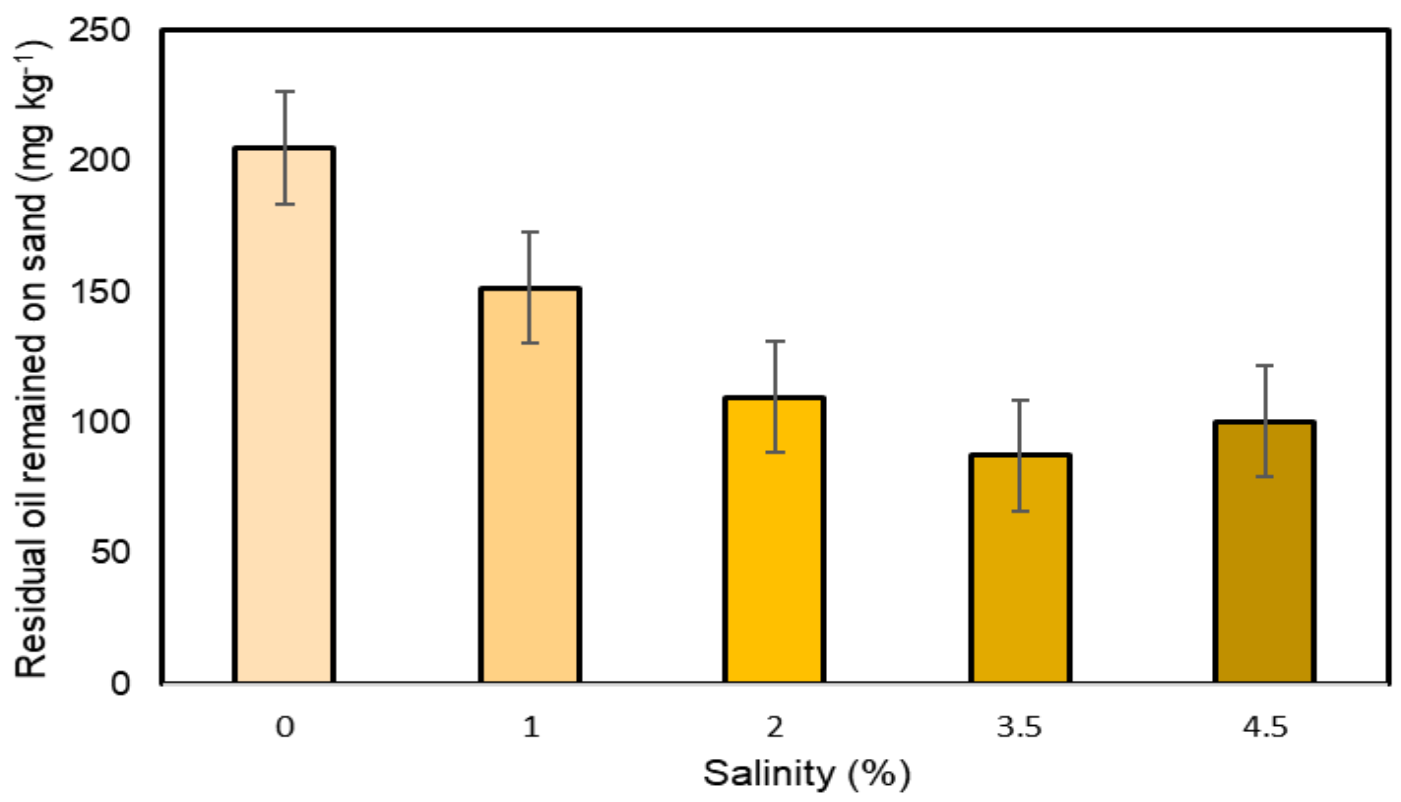

Figure 4-6 The effect salinity on oil behavior in a sand-water system

\subsection{Factorial analysis of environmental conditions and its implications}

A full factorial design with two levels has been conducted to determine the contribution of these influencing factors. In statistics, a full factorial experiment is an experiment whose design consists of two or more factors, each with discrete possible values or "levels", and whose experimental units take on all possible combinations of these levels across all such factors. A full factorial design may also be called a fully crossed design. Such an experiment allows the investigator to study the 
effect of each factor on the response variable, as well as the effects of interactions between factors on the response variable. Figure 4-8(A-D) shows the main plot for four factors with two levels for each factor, which can meet the requirement of factorial design. The detailed contribution of each factor has also been studied with more different levels in previous sections of this manuscript.

In the routine experiments, only one factor can be studied each time with all the other variables being constant, which can hardly reveal the potential interactions among factors on response variables (Zhao et al. 2016). Factorial design can reveal not only the effects of individual parameters but also their relative importance in given process. The interactive effects of two or more variables can also be revealed (Xin et al. 2016). The detected potential interactions among experimental factors will be meaningful for providing a deep insight into the complicated mechanisms or processes under the influences of factors at different levels. In full factorial designs, an experimental run is performed at every combination of factor levels (Shen et al. 2017). Specifically, the two-level factorial design has a sample size that is a power of two, $2^{k}$, where $k$ is the number of factors $\mathrm{He}$ et al. (2018). Thus, in our study, a $2^{4}$ factorial design was determined to study the significant factors and their interactions for the oil behavior, in which four variables were assayed at two levels. The factorial analysis of variance (ANOVA) was performed to identify the main effects of factors and their interactions in oil removal. The effects of the factors would be positive on response if the linear effects are positive. Reversely, the effects of the factor would be negative on response if the linear effects are negative. The statistical significance of individual and interaction effects of the experimental factors was checked by the Fisher F-test, and model terms were evaluated by the p-value with 95\% confidence level (He et al. 2018; Huang et al. 2018). Overall, the factorial design is an effective tool to evaluate the significant impacts of environmental factors and their interactions, which is why we used the method in this study.

The study of interactive effects of various factors can help better under the environmental process (Liu et al. 2020). The statistical analysis results are shown in Table 4-2. Figure 4-7 shows the Pareto chart which presented the main and interaction effects in the process. The effects that are above the reference line are statistically significant at $95 \%$ confidence level. The results showed that the microalgal biomass dose had the most significant effect on the removal of oil. A positive sign of the effect indicated that a high factor setting $(+1)$ would result in a higher oil removal. An 
increase in microalgal biomass dose from $500 \mathrm{ppm}$ to $5000 \mathrm{ppm}$ resulted in the decreased residual oil sand to as low as $34 \%$. The higher biomass concentration may lead to less remained oil due to the more functional groups and active sites toward oil. Since adsorption is a surface-related phenomenon and mircoalgal powder has the internal porosity, they create adsorption forces as well as an adsorptioxin-surface area. Also, due to the small particle size of microalgal powder, surface area is high and may help more on adsorption process. The effects of factors on oil behaviors increased in the following order: biomass dose $>$ temperature $>$ salinity $>\mathrm{pH}$.

Table 4-2 Estimated effects and coefficients for residual oil remained on sand

\begin{tabular}{lllll}
\hline Term & Effect & $\begin{array}{l}\text { Regression } \\
\text { Coefficient }\end{array}$ & Standardized effect & P-value \\
\hline A-Biomass Dose & -3.566 & -1.783 & -4.93 & $<0.001$ \\
B-pH & 1.211 & 0.606 & 1.68 & 0.102 \\
C-Temperature & -2.095 & -1.048 & -2.90 & 0.006 \\
D-Salinity & -2.0 & -1.0 & -2.77 & 0.009 \\
AB & 1.181 & 0.59 & 1.63 & 0.111 \\
BD & 1.134 & 0.567 & 1.57 & 0.125 \\
AD & -1.113 & -0.557 & -1.54 & 0.132 \\
BC & 0.856 & 0.428 & 1.18 & 0.244 \\
\hline
\end{tabular}




\section{Pareto Chart of the Standardized Effects}

(response is Residual oil $(\mathrm{mg} / \mathrm{Kg})$, Alpha $=.05$ )

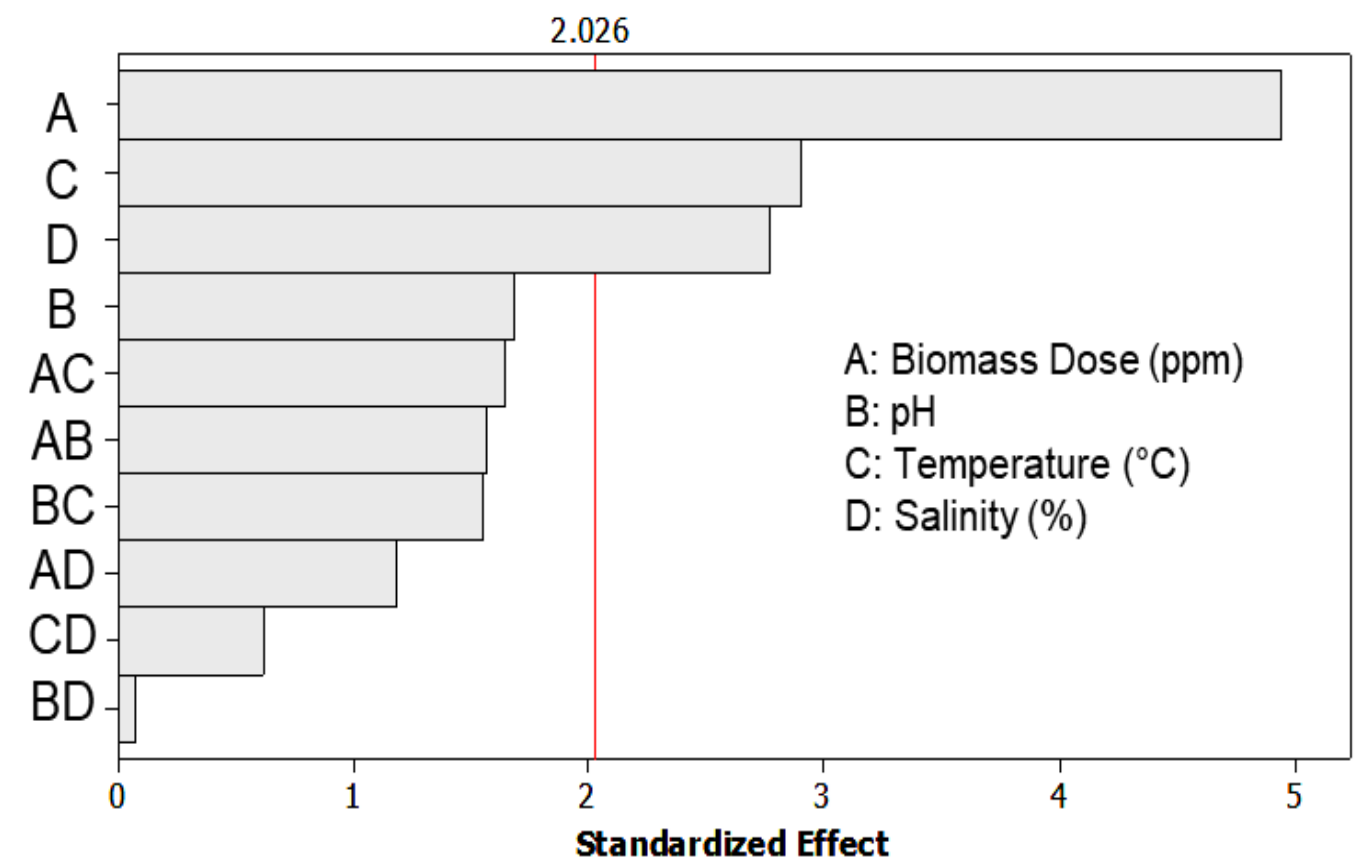

Figure 4-7 Pareto chart for standardized effects for Residual oil remained on sand

The main effects of individual factors on oil remained on sand are shown in Figure 4-8 (A-D). The effect of microalgal biomass dose has been characterized by a greater degree of departure from the overall mean, indicating factor A-biomass dose has a large positive effect on oil removal. The increase of biomass dose resulted in the decrease of remained oil on sand. In the oiled shoreline, the natural oil removal process can be re-evaluated if the high algae amount exists. Temperature and salinity showed a slight and moderate positive effect on oil removal. An increase in temperature and salinity would lead to the decrease of remained oil on sand.

The significant two-factor interaction effects on oil behaviors are shown in Figure 4-8(E-J). It is noted that although the main effects of individual factors B-pH and D-salinity on oil behavior were not as significant as other factors, their interaction effects with other factors were significant. When it referred to two-factor interactions for oil removal process, the interactive effects of $\mathrm{DB}$ and $\mathrm{AB}$ were significant. As seen in Figure 4-8(E), the effect of low-level $\mathrm{pH}$ on oil remained on sand was noticeable with increasing of salinity. When the $\mathrm{pH}$ of solution was at low level, the oil which was remained on sand was only about $525 \mathrm{mg} \mathrm{kg}^{-1}$ under the salinity level of $1 \%$. However, 
approximately $75 \mathrm{mg} \mathrm{kg}^{-1}$ difference in remained oil was observed between the two levels of salinity concentrations in low $\mathrm{pH}$. In low salinity, the amount of oil remained on sand was approximately the same under high and low level of $\mathrm{pH}$. It was also noted that the interactive effects of $\mathrm{pH}$ and microalgal biomass dose were significant (Figure 4-8(F)), while the other interactions among other factors were not significant. Compared with the results from the singlefactor tests, there was a more noticeable difference for the remained oil at different $\mathrm{pH}$ levels with changing microalgal biomass dose. As shown in Figure 4-8(G), there was a slight difference between oil remained on sand under different $\mathrm{pH}$ levels at low level temperature. At high temperature, however, a noticeable difference of the oil remained on sand was observed at high and low levels of $\mathrm{pH}$. Fig. 4-6(H) shows the interactive effect of salinity and microalgal biomass dose on oil remained on sand. It can be seen that the lowest remained oil on sand could be obtained at high salinity level with increasing microalgal biomass dose. The oil remained on sand could also change under various salinity levels at low and high temperature (Figure 4-8(I)). Less oil remained on sand was obtained under high salinity level at high temperature. Figure 4-8(J) shows the interaction of microalgal biomass dose and temperature on oil remained on sand. There was a big difference between oil remained on sand at low and high dose of microalgal biomass at low and high levels of temperature. At high level of microalgal biomass dose, oil remained on sand decreased noticeably with increasing temperature. 


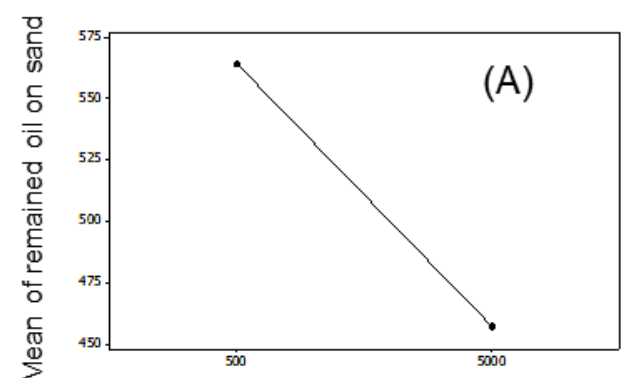

Biomass dose (ppm)

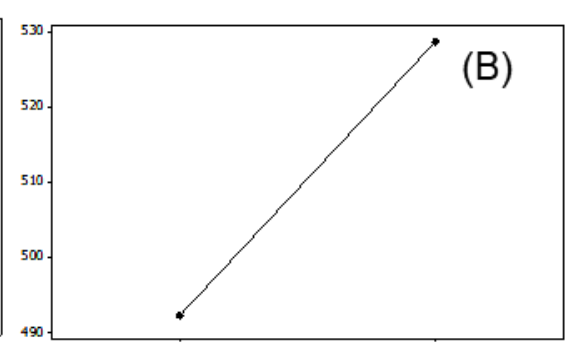

$\mathrm{pH}$

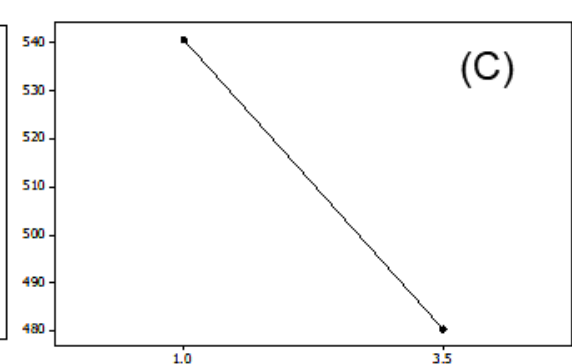

Temperature $\left({ }^{\circ} \mathrm{C}\right)$

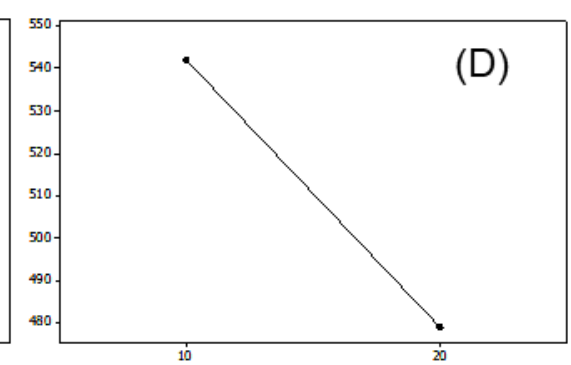

Salinity (\%)
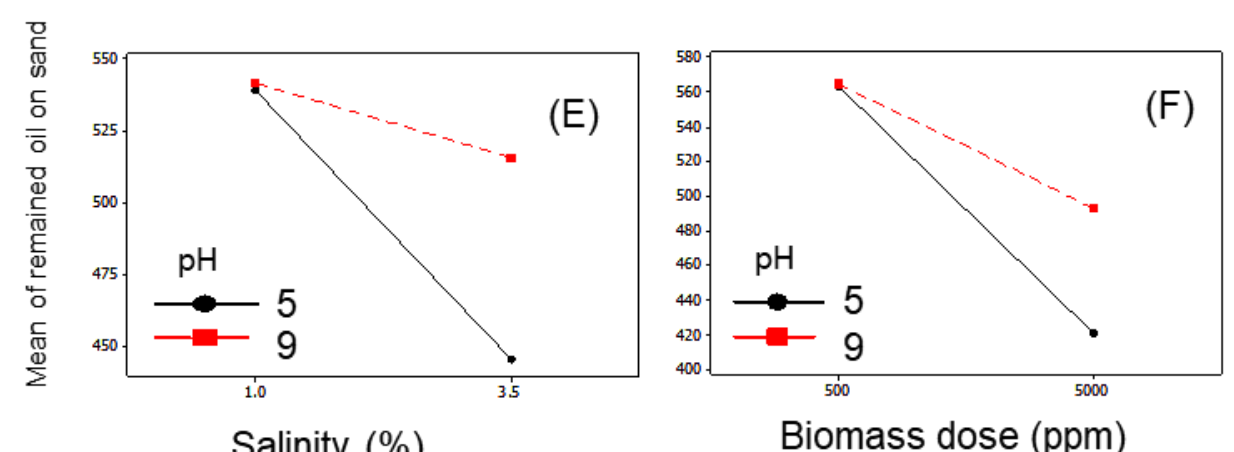

Biomass dose (ppm)
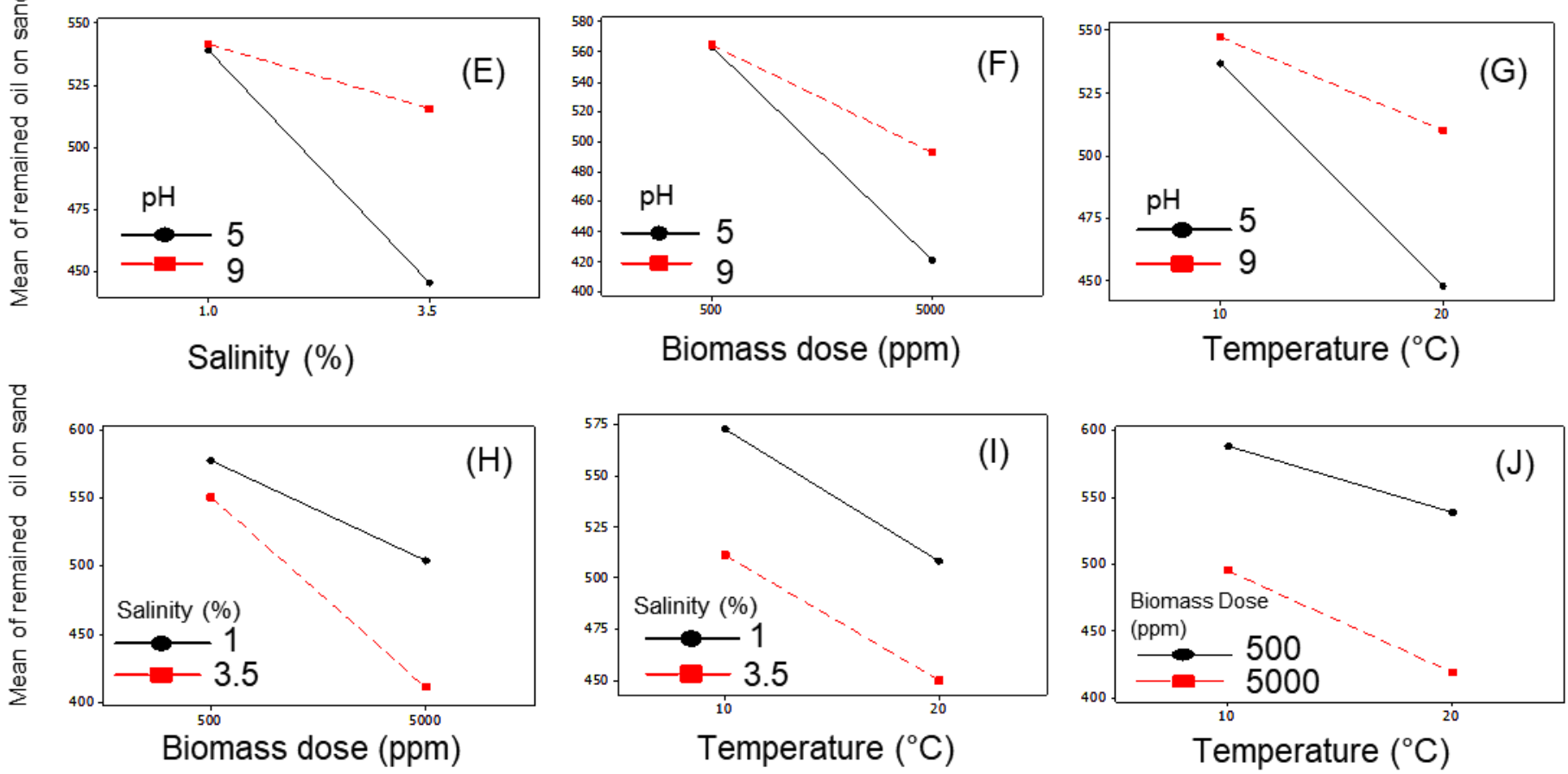

Figure 4-8 (A-D) Main plot for four factors, (E-J) interaction effect plot for each two factors. 


\section{CHAPTER 5. CONCLUSIONS}

\subsection{Summary}

In this study, the effects of microalgal biomass on the oil behavior in a sand-water system has been investigated. The microalgal biomass was characterized and the interaction between microalgae and oil was analyzed through FTIR. The effects of different conditions including microalgal biomass dose, $\mathrm{pH}$, temperature and salinity on the oil behavior were investigated. A two-level factorial analysis was also used to further explore the interactions of these conditions. The microalgal biomass was found to be the most influential parameter for the residual crude oil on sand. Higher microalgal biomass dose resulted in less residual oil on sand. The remaining oil decreased with increasing solution $\mathrm{pH}$ from 4 to 7 , and an increase of remaining oil was observed when the $\mathrm{pH}$ was further increased above 7. In addition, temperature and salinity could affect the removal of crude oil in the presence of microalgal biomass. The behaviors of oil in this sand-water system could be influenced by the solution chemistry. The results of this study indicate that the presence of algae in the oilcontaminated shoreline can be considered in the comprehensive evaluation of spill risk and prediction of oil fate. Further study is also required to investigate the impact of oil characteristics and obtain more theoretical foundation for oil mobility under various shoreline environmental conditions.

\subsection{Recommendation for future study}

The potential of using biomass as biosorbent for organic pollutant sorption has been studied. $\mathrm{pH}$, temperature and ion strength are important factors affecting the rate of biosorption. In different literature, it has been found that most of the research has been limited to single PAH compound biosorption. Biosorption of other organic pollutants such as crude oil and mixed PAH are still in blooming stage, with huge unexplored aspects. This aspect needs to be addressed as in nature more than one compound could be present that may affect the biosorption and degradation of one on the other. $\mathrm{pH}$ of biosorption medium is the most important parameter influencing the biosorption capacity. Components of pyruvate dehydrogenase complex have been reported in various studies suggesting key role of the enzyme in degradation of PAH compounds. However, more elaborative research is required to understand other enzymes and mechanism responsible in the degradation of PAHs. 
The studies on water soluble hydrocarbon fraction are still limited, with a knowledge gap relative to environmental effects on organic pollutants removal. Biosorption is a ubiquitous property of living or dead biomass and derived products, and is undoubtedly an important process in the environment, and in several conventional waste treatment processes. It has been proposed as a cheap and effective biotechnology for many years, yet has had extremely limited industrial exploitation to date.

In the field of biosorption, microorganisms such as algae, bacteria, fungi have gained immense attention for their abilities to accumulate organic pollutants in their cell structures. However, research studies exploring the utilization of microalgae in biosorption of organic contaminants such as Crude oil and PAHs are limited. Common suggestions for future research directions include identification of better and more selective biosorbents, more development of biosorption models and identification of biosorption mechanisms, and further assessments of market size, and costs of development. The potential of biosorption can be further improved by evaluating the biomass removal capacity for the most water-soluble hydrocarbons (benzene and toluene) under controlled laboratory conditions to increase our knowledge of its use for remediation purposes. 


\section{REFERENCES}

Ahmad A, Bhatia S, Ibrahim N, Sumathi S (2005a) Adsorption of residual oil from palm oil mill effluent using rubber powder. Brazilian Journal of Chemical Engineering 22:371-379

Ahmad A, Sumathi S, Hameed B (2005b) Adsorption of residue oil from palm oil mill effluent using powder and flake chitosan: equilibrium and kinetic studies. Water Research 39:24832494

Aksu Z, Tezer S (2005) Biosorption of reactive dyes on the green alga Chlorella vulgaris. Process Biochemistry 40:1347-1361

Al-Shamrani A, James A, Xiao H (2002) Destabilisation of oil-water emulsions and separation by dissolved air flotation. Water Research 36:1503-1512

An C, Huang G (2012) Stepwise adsorption of phenanthrene at the fly ash-water interface as affected by solution chemistry: experimental and modeling studies. Environmental Science \& Technology 46:12742-12750

An C, Huang G, Yao Y, Zhao S (2017) Emerging usage of electrocoagulation technology for oil removal from wastewater: a review. Science of the Total Environment 579:537-556

Anastopoulos I, Kyzas GZ (2015) Progress in batch biosorption of heavy metals onto algae. Journal of Molecular Liquids 209:77-86

Anderson WC (1997) Innovative Site Remediation Technology, Design \& Application, Volume 5: Thermal Desorption vol 5. US Environmental Protection Agency, Solid Waste and Emergency Response,

Annunciado T, Sydenstricker T, Amico S (2005) Experimental investigation of various vegetable fibers as sorbent materials for oil spills. Marine Pollution Bulletin 50:1340-1346

Arief VO, Trilestari K, Sunarso J, Indraswati N, Ismadji S (2008) Recent progress on biosorption of heavy metals from liquids using low cost biosorbents: characterization, biosorption parameters and mechanism studies. CLEAN-Soil, Air, Water 36:937-962

Asemani M, Rabbani AR (2020) Detailed FTIR spectroscopy characterization of crude oil extracted asphaltenes: Curve resolve of overlapping bands. Journal of Petroleum Science and Engineering 185:106618

Atykyan N, Revin V, Shutova V (2020) Raman and FT-IR Spectroscopy investigation the cellulose structural differences from bacteria Gluconacetobacter sucrofermentans during the different regimes of cultivation on a molasses media. AMB Express 10:1-11 
Avery SV, Codd GA, Gadd GM (1998) Microalgal removal of organic and inorganic metal species from aqueous solution. In: Wastewater treatment with algae. Springer, pp 55-72

Beolchini F, Pagnanelli F, Toro L, Veglio F (2006) Ionic strength effect on copper biosorption by Sphaerotilus natans: equilibrium study and dynamic modelling in membrane reactor. Water Research 40:144-152

Bilal M, Rasheed T, Sosa-Hernández JE, Raza A, Nabeel F, Iqbal H (2018) Biosorption: an interplay between marine algae and potentially toxic elements - a review. Marine Drugs $16: 65$

Boleydei H, Mirghaffari N, Farhadian O (2018) Comparative study on adsorption of crude oil and spent engine oil from seawater and freshwater using algal biomass. Environmental Science and Pollution Research 25:21024-21035

Broman D, Ganning B, Lindblad C (1983) Effects of high pressure, hot water shore cleaning after oil spills on shore ecosystems in the Northern Baltic proper. Marine environmental research 10:173-187

Cai L et al. (2019) Effective adsorption of diesel oil by crab-shell-derived biochar nanomaterials. Materials 12:236

Carolin CF, Kumar PS, Saravanan A, Joshiba GJ, Naushad M (2017) Efficient techniques for the removal of toxic heavy metals from aquatic environment: A review. Journal of Environmental Chemical Engineering 5:2782-2799

Chan SMN, Luan T, Wong MH, Tam NFY (2006) Removal and biodegradation of polycyclic aromatic hydrocarbons by Selenastrum capricornutum. Environmental Toxicology and Chemistry: An International Journal 25:1772-1779

Chekroun KB, Sánchez E, Baghour M (2014) The role of algae in bioremediation of organic pollutants. Journal Issues ISSN 2360:8803

Chen B, Wang Y, Hu D (2010) Biosorption and biodegradation of polycyclic aromatic hydrocarbons in aqueous solutions by a consortium of white-rot fungi. Journal of Hazardous materials 179:845-851

Chen $\mathrm{Z}$ et al. (2019) Use of surface-washing agents for the treatment of oiled shorelines: research advancements, technical applications and future challenges. Chemical Engineering Journal: 123565 
Cheng Z et al. (2020) Novel biosorbents synthesized from fungal and bacterial biomass and their applications in the adsorption of volatile organic compounds. Bioresource Technology $300: 122705$

Cheu SC, Kong H, Song ST, Johari K, Saman N, Yunus MAC, Mat H (2016) Separation of dissolved oil from aqueous solution by sorption onto acetylated lignocellulosic biomassequilibrium, kinetics and mechanism studies. Journal of Environmental Chemical Engineering 4:864-881

Choi HM, Moreau JP (1993) Oil sorption behavior of various sorbents studied by sorption capacity measurement and environmental scanning electron microscopy. Microscopy Research and Technique 25:447-455

Chojnacka K (2010) Biosorption and bioaccumulation-the prospects for practical applications. Environment International 36:299-307

Chojnacka K, Chojnacki A, Gorecka H (2005) Biosorption of $\mathrm{Cr} 3+, \mathrm{Cd} 2+$ and $\mathrm{Cu} 2+$ ions by bluegreen algae Spirulina sp.: kinetics, equilibrium and the mechanism of the process. Chemosphere 59:75-84

Chu K, Hashim M, Phang S, Samuel V (1997) Biosorption of cadmium by algal biomass: adsorption and desorption characteristics. Water Science and Technology 35:115-122

Chung M, Tsui MT, Cheung K, Tam NF, Wong MH (2007) Removal of aqueous phenanthrene by brown seaweed Sargassum hemiphyllum: Sorption-kinetic and equilibrium studies. Separation and Purification Technology 54:355-362

Cleary DF, Polónia AR, de Voogd NJ (2018) Bacterial communities inhabiting the sponge Biemna fortis, sediment and water in marine lakes and the open sea. Microbial Ecology 76:610-624

Crist RH, Oberholser K, Shank N, Nguyen M (1981) Nature of bonding between metallic ions and algal cell walls. Environmental Science \& Technology 15:1212-1217

de Rome L, Gadd GM (1987) Copper adsorption by Rhizopus arrhizus, Cladosporium resinae and Penicillium italicum. Applied Microbiology and Biotechnology 26:84-90

Deivakumari M, Sanjivkumar M, Suganya A, Prabakaran JR, Palavesam A, Immanuel G (2020) Studies on reclamation of crude oil polluted soil by biosurfactant producing Pseudomonas aeruginosa (DKB1). Biocatalysis and Agricultural Biotechnology 29:101773

Devi MG, Al-Hashmi ZS, Sekhar GC (2012) Treatment of vegetable oil mill effluent using crab shell chitosan as adsorbent. International Journal of Environmental Science and Technology 9:713-718 
Díaz E (2004) Bacterial degradation of aromatic pollutants: a paradigm of metabolic versatility.

Ding J, Chen B, Zhu L (2013) Biosorption and biodegradation of polycyclic aromatic hydrocarbons by Phanerochaete chrysosporium in aqueous solution. Chinese Science Bulletin 58:613-621

Doyle RJ, Matthews TH, Streips UN (1980) Chemical basis for selectivity of metal ions by the Bacillus subtilis cell wall. Journal of Bacteriology 143:471-480

El-Sheekh M, El Sabagh S, Abou El-Souod G, Elbeltagy A (2019) Biosorption of cadmium from aqueous solution by free and immobilized dry biomass of chlorella vulgaris. International Journal of Environmental Research 13:511-521

El-Sheekh MM, Ghareib M, Abou-El-Souod G (2012) Biodegradation of phenolic and polycyclic aromatic compounds by some algae and cyanobacteria. Journal of Bioremediation and Biodegradation 3

Flores-Chaparro CE, Ruiz LFC, de la Torre MCA, Huerta-Diaz MA, Rangel-Mendez JR (2017) Biosorption removal of benzene and toluene by three dried macroalgae at different ionic strength and temperatures: Algae biochemical composition and kinetics. Journal of Environmental Management 193:126-135

Flouty R, Estephane G (2012) Bioaccumulation and biosorption of copper and lead by a unicellular algae Chlamydomonas reinhardtii in single and binary metal systems: a comparative study. Journal of Environmental Management 111:106-114

Gadd G, Gray D, Newby P (1990) Role of melanin in fungal biosorption of tributyltin chloride. Applied Microbiology and Biotechnology 34:116-121

Gadd GM (2009) Biosorption: critical review of scientific rationale, environmental importance and significance for pollution treatment. Journal of Chemical Technology \& Biotechnology: International Research in Process, Environmental \& Clean Technology 84:13-28

Ghadiryanfar M, Rosentrater KA, Keyhani A, Omid M (2016) A review of macroalgae production, with potential applications in biofuels and bioenergy. Renewable and Sustainable Energy Reviews 54:473-481

Gordon Jr DC, Keizer PD, Prouse NJ (1973) Laboratory studies of the accommodation of some crude and residual fuel oils in sea water. Journal of the Fisheries Board of Canada 30:16111618

Gupta V, Rastogi A (2009) Biosorption of hexavalent chromium by raw and acid-treated green alga Oedogonium hatei from aqueous solutions. Journal of Hazardous materials 163:396-402 
Hadjoudja S, Deluchat V, Baudu M (2010) Cell surface characterisation of Microcystis aeruginosa and Chlorella vulgaris. Journal of Colloid and Interface Science 342:293-299

Hao W, Yanpeng L, Zhou S, Xiangying R, Wenjun Z, Jun L (2017) Surface characteristics of microalgae and their effects on harvesting performance by air flotation. International Journal of Agricultural and Biological Engineering 10:125-133

He Y, Huang G, An C, Huang J, Zhang P, Chen X, Xin X (2018) Reduction of Escherichia Coli using ceramic disk filter decorated by nano-TiO2: A low-cost solution for household water purification. The Science of the total environment 616-617:1628-1637 doi:10.1016/j.scitotenv.2017.10.149

Henriques B et al. (2017) A macroalgae-based biotechnology for water remediation: Simultaneous removal of $\mathrm{Cd}, \mathrm{Pb}$ and $\mathrm{Hg}$ by living Ulva lactuca. Journal of Environmental Management 191:275-289

Hernández-García A, Velásquez-Orta SB, Novelo E, Yáñez-Noguez I, Monje-Ramírez I, Ledesma MTO (2019) Wastewater-leachate treatment by microalgae: Biomass, carbohydrate and lipid production. Ecotoxicology and Environmental safety 174:435-444

Ho S-H, Huang S-W, Chen C-Y, Hasunuma T, Kondo A, Chang J-S (2013) Bioethanol production using carbohydrate-rich microalgae biomass as feedstock. Bioresource Technology 135:191-198

Huang J, Huang G, An C, He Y, Yao Y, Zhang P, Shen J (2018) Performance of ceramic disk filter coated with nano $\mathrm{ZnO}$ for removing Escherichia coli from water in small rural and remote communities of developing regions. Environmental pollution 238:52-62 doi:10.1016/j.envpol.2018.03.008

Ibrahim S, Wang S, Ang HM (2010) Removal of emulsified oil from oily wastewater using agricultural waste barley straw. Biochemical Engineering Journal 49:78-83

Ibrahim WM, Hassan AF, Azab YA (2016) Biosorption of toxic heavy metals from aqueous solution by Ulva lactuca activated carbon. Egyptian journal of basic and applied sciences 3:241-249

Johnson JA, Edwards DA, Blue D, Morey SJ (2018) Physical properties of oil-particle aggregate (OPA)-containing sediments. Soil and Sediment Contamination 27:706-722

Khan E, Virojnagud W, Ratpukdi T (2004) Use of biomass sorbents for oil removal from gas station runoff. Chemosphere 57:681-689 
Kim N, Seo JH, Yun Y-S, Park D (2020) New insight into continuous recirculation-process for treating arsenate using bacterial biosorbent. Bioresource Technology 316:123961

Koelmans AA, Anzion SF, Lijklema L (1995) Dynamics of organic micropollutant biosorption to cyanobacteria and detritus. Environmental Science \& Technology 29:933-940

Kök MV, Varfolomeev MA, Nurgaliev DK (2017) Crude oil characterization using tga-dta, tga-ftir and tga-ms techniques. Journal of Petroleum Science and Engineering 154:537-542

Kolenbrander P, Ensign J (1968) Isolation and chemical structure of the peptidoglycan of Spirillum serpens cell walls. Journal of Bacteriology 95:201-210

Kumar G et al. (2019) Effects of light intensity on biomass, carbohydrate and fatty acid compositions of three different mixed consortia from natural ecological water bodies. Journal of Environmental Management 230:293-300

Kumar R, Bishnoi NR, Bishnoi K (2008) Biosorption of chromium (VI) from aqueous solution and electroplating wastewater using fungal biomass. Chemical Engineering Journal 135:202-208

Le Floch S, Guyomarch J, Merlin F-X, Stoffyn-Egli P, Dixon J, Lee K (2002) The influence of salinity on oil-mineral aggregate formation. Spill Science \& Technology Bulletin 8:65-71

Lee K (2002) Oil-particle interactions in aquatic environments: influence on the transport, fate, effect and remediation of oil spills. Spill Sci. Technol. Bull. Spill Science \& Technology Bulletin

Lee MY, Hong KJ, Kajiuchi T, Yang JW (2004) Determination of the efficiency and removal mechanism of cobalt by crab shell particles. Journal of Chemical Technology \& Biotechnology: International Research in Process, Environmental \& Clean Technology 79:1388-1394

Lei A, Wong Y, Tam N (2002) Removal of pyrene by different microalgal species. Water Science and Technology 46:195-201

Lei AP, Hu ZL, Wong YS, Tam NFY (2007) Removal of fluoranthene and pyrene by different microalgal species. Bioresource Technology 98:273-280

Lim MW, Von Lau E, Poh PE (2016) A comprehensive guide of remediation technologies for oil contaminated soil—present works and future directions. Marine Pollution Bulletin 109:1445

Lin DQ, Brixius PJ, Hubbuch JJ, Thömmes J, Kula MR (2003) Biomass/adsorbent electrostatic interactions in expanded bed adsorption: a zeta potential study. Biotechnology and Bioengineering 83:149-157 
Liu Q, Dong M, Asghari K, Tu Y (2007) Wettability alteration by magnesium ion binding in heavy $\mathrm{oil} / \mathrm{brine} / \mathrm{chemical} /$ sand systems - Analysis of electrostatic forces. Journal of Petroleum Science and Engineering 59:147-156

Liu Y, Huang G, An C, Chen X, Zhang P, Feng R, Xiong W (2020) Use of nano-TiO2 selfassembled flax fiber as a new initiative for immiscible oil/water separation. Journal of Hazardous materials 249:119352

Luo L, Wang P, Lin L, Luan T, Ke L, Tam NFY (2014) Removal and transformation of high molecular weight polycyclic aromatic hydrocarbons in water by live and dead microalgae. Process Biochemistry 49:1723-1732

Ma R et al. (2018) LED power efficiency of biomass, fatty acid, and carotenoid production in Nannochloropsis microalgae. Bioresource Technology 252:118-126

Majumder R, Sheikh L, Naskar A, Mukherjee M, Tripathy S (2017) Depletion of Cr (VI) from aqueous solution by heat dried biomass of a newly isolated fungus Arthrinium malaysianum: A mechanistic approach. Scientific Reports 7:1-15

Malik D, Strelko Jr V, Streat M, Puziy A (2002) Characterisation of novel modified active carbons and marine algal biomass for the selective adsorption of lead. Water Research 36:1527-1538

Marbelia L, Mulier M, Vandamme D, Muylaert K, Szymczyk A, Vankelecom IF (2016) Polyacrylonitrile membranes for microalgae filtration: Influence of porosity, surface charge and microalgae species on membrane fouling. Algal research 19:128-137

Mata TM, Martins AA, Caetano NS (2010) Microalgae for biodiesel production and other applications: a review. Renewable and Sustainable Energy Reviews 14:217-232

McDonald L, Trevors J (1988) Review of tin resistance, accumulation and transformations by microorganisms. Water, Air, and Soil Pollution 40:215-221

Mishra PK, Mukherji S (2012) Biosorption of diesel and lubricating oil on algal biomass. 3 Biotech $2: 301-310$

Mokhtarian N, Talaie AR, Jaafarzadeh N, Talaie MR, Beheshti M (2010) Producing biosurfactants from Purified microorganisms obtained from oil-contaminated soil. J. of Water and Wastewater 75:20-27

Muñoz R, Alvarez MT, Muñoz A, Terrazas E, Guieysse B, Mattiasson B (2006) Sequential removal of heavy metals ions and organic pollutants using an algal-bacterial consortium. Chemosphere 63:903-911 
Muschenheim D, Lee K (2002) Removal of oil from the sea surface through particulate interactions: review and prospectus. Spill Science \& Technology Bulletin 8:9-18

Nabavi SM, Silva AS (2018) Nonvitamin and nonmineral nutritional supplements. Academic Press,

Nigam PS, Singh A (2011) Production of liquid biofuels from renewable resources. Progress in Energy and Combustion Science 37:52-68

No HK, Meyers SP, Lee KS (1989) Isolation and characterization of chitin from crawfish shell waste. Journal of Agricultural and Food Chemistry 37:575-579

Nwokoma DB, Anene U (2010) Adsorption of crude oil using meshed groundnut husk. Chemical Product and Process Modeling 5:9

Owens EH, Taylor E, Humphrey B (2008) The persistence and character of stranded oil on coarsesediment beaches. Marine Pollution Bulletin 56:14-26

Park D, Yun Y-S, Park JM (2010) The past, present, and future trends of biosorption. Biotechnology and Bioprocess Engineering 15:86-102

Passow U, Ziervogel K (2016) Marine snow sedimented oil released during the Deepwater Horizon spill. Journal of the Oceanographical Society of Japan 29:118-125

Pathak B, Gupta S, Verma R (2018) Biosorption and biodegradation of polycyclic aromatic hydrocarbons (PAHs) by microalgae. In: Green Adsorbents for Pollutant Removal. Springer, pp 215-247

Peña-Rodríguez A, Mawhinney TP, Ricque-Marie D, Cruz-Suárez LE (2011) Chemical composition of cultivated seaweed Ulva clathrata (Roth) C. Agardh. Food Chemistry 129:491-498

Puranik P, Modak J, Paknikar K (1999) A comparative study of the mass transfer kinetics of metal biosorption by microbial biomass. Hydrometallurgy 52:189-197

Rae IB, Gibb SW, Lu S (2009) Biosorption of Hg from aqueous solutions by crab carapace. Journal of Hazardous materials 164:1601-1604

Raghukumar C, Shailaja M, Parameswaran P, Singh S (2006) Removal of polycyclic aromatic hydrocarbons from aqueous media by the marine fungus NIOCC 312: Involvement of lignin-degrading enzymes and exopolysaccharides.

Rajaković-Ognjanović V, Aleksić G, Rajaković L (2008) Governing factors for motor oil removal from water with different sorption materials. Journal of Hazardous materials 154:558-563 
Ramrakhiani L, Majumder R, Khowala S (2011) Removal of hexavalent chromium by heat inactivated fungal biomass of Termitomyces clypeatus: surface characterization and mechanism of biosorption. Chemical Engineering Journal 171:1060-1068

Rangabhashiyam S, Suganya E, Selvaraju N, Varghese LA (2014) Significance of exploiting nonliving biomaterials for the biosorption of wastewater pollutants. World Journal of Microbiology and Biotechnology 30:1669-1689

Rao J, Viraraghavan T (2002) Biosorption of phenol from an aqueous solution by Aspergillus niger biomass. Bioresource Technology 85:165-171

REED RH, COLLINS JC, RUSSELL G (1980) The effects of salinity upon cellular volume of the marine red alga Porphyra purpurea (Roth) C. Ag. Journal of Experimental Botany 31:15211537

Riley BJ, Lennard C, Fuller S, Spikmans V (2016) An FTIR method for the analysis of crude and heavy fuel oil asphaltenes to assist in oil fingerprinting. Forensic Science International 266:555-564

Safi C, Zebib B, Merah O, Pontalier PY, Vaca Garcia C (2014) Morphology, composition, production, processing and applications of Chlorella vulgaris: A review. Renewable and Sustainable Energy Reviews 35:265-278

Safonova E, Kvitko K, Kuschk P, Möder M, Reisser W (2005) Biodegradation of Phenanthrene by the Green Alga Scenedesmus obliquus ES-55. Engineering in Life Sciences 5:234-239

Sar1 A, Tuzen M (2008) Biosorption of Pb (II) and Cd (II) from aqueous solution using green alga (Ulva lactuca) biomass. Journal of Hazardous materials 152:302-308

Seltmann G, Holst O (2013) The bacterial cell wall. Springer Science \& Business Media,

Sharma R, Singh NS, Dhingra N, Parween T (2020) Bioremediation of oil-spills from shoreline environment. In: Modern age waste water problems. Springer, pp 275-291

Shen J, Huang G, An C, Zhao S, Rosendahl S (2017) Immobilization of tetrabromobisphenol A by pinecone-derived biochars at solid-liquid interface: Synchrotron-assisted analysis and role of inorganic fertilizer ions. Chem. Eng. J 321:346-357 doi:10.1016/j.cej.2017.03.138

Simelane LP, Fosso-Kankeu E, Njobeh P, Pandey S (2018) Response of bacterial biosorbents to chemical treatment as influenced by cell membrane structure and impact on the adsorption behaviour of dyes. Current Science 114:826-834 
St-Louis R, Pelletier E, Marsot P (1997) A mechanistic approach to tributyltin (TBT) sorption by marine microflagellated alga Pavlova lutheri. Applied Organometallic Chemistry 11:543550

Stringfellow WT, Alvarez-Cohen L (1999) Evaluating the relationship between the sorption of PAHs to bacterial biomass and biodegradation. Water Research 33:2535-2544

Swackhamer DL, Skoglund R (1993) Bioaccumulation of PCBs by algae: kinetics versus equilibrium. Environmental Toxicology and Chemistry: An International Journal 12:831838

Tam NF, Chong A, Wong Y (2002) Removal of tributyltin (TBT) by live and dead microalgal cells. Marine Pollution Bulletin 45:362-371

Tao K, Zhang X, Chen X, Liu X, Hu X, Yuan X (2019) Response of soil bacterial community to bioaugmentation with a plant residue-immobilized bacterial consortium for crude oil removal. Chemosphere 222:831-838

Tian Y, Li J, Whitcombe TW, McGill WB, Thring R (2020) Application of oily sludge-derived char for lead and cadmium removal from aqueous solution. Chemical Engineering Journal $384: 123386$

Toyoda M, Moriya K, Aizawa J-i, Konno H, Inagaki M (2000) Sorption and recovery of heavy oils by using exfoliated graphite Part I: Maximum sorption capacity. Desalination 128:205-211

Tsezos M (1983) The role of chitin in uranium adsorption by R. arrhizus. Biotechnology and Bioengineering 25:2025-2040

Tsezos M, Bell J (1989) Comparison of the biosorption and desorption of hazardous organic pollutants by live and dead biomass. Water Research 23:561-568

Urum K, Pekdemir T, Çopur M (2004) Surfactants treatment of crude oil contaminated soils. Journal of Colloid and Interface Science 276:456-464

Vandevivere P, Kirchman DL (1993) Attachment stimulates exopolysaccharide synthesis by a bacterium. Applied and Environmental Microbiology 59:3280-3286

Vijayaraghavan K, Yun Y-S (2008) Bacterial biosorbents and biosorption. Biotechnology Advances 26:266-291

Wang J, Chen C (2006) Biosorption of heavy metals by Saccharomyces cerevisiae: a review. Biotechnology Advances 24:427-451

Wang J, Chen C (2009) Biosorbents for heavy metals removal and their future. Biotechnology Advances 27:195-226 
Wang X, Zheng X, Shen Y, Wang T (2017) Biosorption kinetics and mechanisms of low concentration uranium by live and heat-killed Saccharomyces cerevisiae. Acta Scientiae Circumstantiae 37:169-177

Wasko M, Bratt R (1991) Properties of a biosurfactant produced by the fuel contaminant Ochrobactrum anthropii. International biodeterioration 27:265-273

Widrig DL, Gray KA, McAuliffe KS (1996) Removal of algal-derived organic material by preozonation and coagulation: monitoring changes in organic quality by pyrolysis-GC-MS. Water Research 30:2621-2632

Wong-Ng J, Celani A, Vergassola M (2018) Exploring the function of bacterial chemotaxis. Current Opinion in Microbiology 45:16-21

Xin X, Huang G, An C, Feng R (2019a) Interactive toxicity of triclosan and nano-TiO2 to green alga eremosphaera viridis in lake Erie: A new perspective based on fourier transform infrared spectromicroscopy and synchrotron-based X-ray fluorescence imaging. Environmental Science \& Technology 53:9884-9894

Xin X et al. (2018) Insights into the toxicity of triclosan to green microalga Chlorococcum sp. using synchrotron-based fourier transform infrared spectromicroscopy: biophysiological analyses and roles of environmental factors. Environmental Science \& Technology 52:2295-2306

Xin X, Huang G, An C, Lu C, Xiong W (2020) Exploring the biophysicochemical alteration of green alga Asterococcus superbus interactively affected by nanoparticles, triclosan and illumination. Journal of Hazardous materials:122855

Xin X, Huang G, An C, Weger H, Cheng G, Shen J, Rosendahl S (2019b) Analyzing the biochemical alteration of green algae during chronic exposure to triclosan based on synchrotron-based Fourier transform infrared Spectromicroscopy. Analytical Chemistry 91:7798-7806

Xin X, Huang G, Sun W, Zhou Y, Fan Y (2016) Factorial Two-Stage Irrigation System Optimization Model. Journal of Irrigation and Drainage Engineering 142:04015056 doi:10.1061/(asce)ir.1943-4774.0000951

$\mathrm{Xu} \mathrm{J}, \mathrm{Wu}$ L, Chang AC (2009) Degradation and adsorption of selected pharmaceuticals and personal care products (PPCPs) in agricultural soils. Chemosphere 77:1299-1305

Xu N, Bao M, Sun P, Li Y (2013) Study on bioadsorption and biodegradation of petroleum hydrocarbons by a microbial consortium. Bioresource Technology 149:22-30 
Zeraatkar AK, Ahmadzadeh H, Talebi AF, Moheimani NR, McHenry MP (2016) Potential use of algae for heavy metal bioremediation, a critical review. Journal of Environmental Management 181:817-831

Zhang C, Lu J, Wu J (2019a) Adsorptive removal of polycyclic aromatic hydrocarbons by detritus of green tide algae deposited in coastal sediment. Science of the Total Environment 670:320-327

Zhang C, Lu J, Wu J, Luo Y (2017) Removal of phenanthrene from coastal waters by green tide algae Ulva prolifera. Science of the Total Environment 609:1322-1328

Zhang Y, Zhu C, Liu F, Yuan Y, Wu H, Li A (2019b) Effects of ionic strength on removal of toxic pollutants from aqueous media with multifarious adsorbents: A review. Science of the Total Environment 646:265-279

Zhao S, Huang G, Wang S, Wang X, Huang W (2016) Insight into sorption mechanism of phenanthrene onto gemini modified palygorskite through a multi-level fuzzy-factorial inference approach. Environmental Letters 51:759-768

Zhao S, Huang W, Wang X, Fan Y, An C (2019) Sorption of phenanthrene onto diatomite under the influences of solution chemistry: A study of linear sorption based on maximal information coefficient. Journal of Environmental Informatics 34:35-44

Zhou JL, Kiff RJ (1991) The uptake of copper from aqueous solution by immobilized fungal biomass. Journal of Chemical Technology \& Biotechnology 52:317-330 